\title{
Development of a novel hybrid bioactive hydrogel for future clinical applications
}

Journal of Biomaterials Applications 20I8, Vol. 33(3) 447-465 (C) The Author(s) 2018 Article reuse guidelines: sagepub.com/journals-permissions DOI: 10.1 |77/0885328218794|63 journals.sagepub.com/home/jba (S)AGE

\author{
Lydia Francis', Karin V Greco' (D), Aldo R Boccaccini², \\ Judith J Roether ${ }^{2}$, Nicholas R English ${ }^{3}$, Honglei Huang ${ }^{4}$, \\ R Ploeg ${ }^{4}$ and Tahera Ansari ${ }^{\prime}$
}

\begin{abstract}
Three-dimensional hydrogels are ideal for tissue engineering applications due to their structural integrity and similarity to native soft tissues; however, they can lack mechanical stability. Our objective was to develop a bioactive and mechanically stable hydrogel for clinical application. Auricular cartilage was decellularised using a combination of hypertonic and hypotonic solutions with and without enzymes to produce acellular tissue. Methacryloyl groups were crosslinked with alginate and PVA main chains via 2-aminoethylmathacrylate and the entire macromonomer further crosslinked with the acellular tissue. The resultant hydrogels were characterised for its physicochemical properties (using NMR), in vitro degradation (via GPC analysis), mechanical stability (compression tests) and in vitro biocompatibility (co-culture with bone marrow-derived mesenchymal stem cells). Following decellularisation, the cartilage tissue showed to be acellular at a significant level (DNA content $25.33 \mathrm{ng} / \mathrm{mg}$ vs. $351.46 \mathrm{ng} / \mathrm{mg}$ control tissue), with good structural and molecular integrity of the retained extra cellular matrix (s-GAG $=0.19 \mu \mathrm{g} / \mathrm{mg}$ vs. $0.65 \mu \mathrm{g} / \mathrm{mg} \pm 0.00$ I control tissue). Proteomic analysis showed that collagen subtypes and proteoglycans were retained, and SEM and TEM showed preserved matrix ultra-structure. The hybrid hydrogel was successfully cross-linked with biological and polymer components, and it was stable for 30 days in simulated body fluid (poly dispersal index for alginate with tissue was stable at I.08 and for PVA with tissue was stable at I.I6). It was also mechanically stable (Young's modulus of $0.46 \pm 0.3 \mathrm{I} \mathrm{KPa)} \mathrm{and} \mathrm{biocompatible,} \mathrm{as} \mathrm{it}$ was able to support the development of a multi-cellular feature with active cellular proliferation in vitro. We have shown that it is possible to successfully combine biological tissue with both a synthetic and natural polymer and create a hybrid bioactive hydrogel for clinical application.
\end{abstract}

\section{Keywords}

Cartilage, hydrogel, scaffold, biocompatible, hybrid

\section{Introduction}

Biomaterials play a crucial role in regenerative medicine and pharmaceutical therapies, e.g. drug delivery. Hydrogels are biomaterials chosen for their hydrophilic nature, which allows them to absorb and retain large amounts of water thereby mimicking hydrated tissues. ${ }^{1}$ In their swollen state, these biomaterials can facilitate the transport of nutrients into cells and removal of cellular waste. ${ }^{1}$

Three-dimensional (3D) hydrogels are ideal for tissue engineering applications due to their structural integrity which is similar to native soft tissues. Hydrogels with large interconnected pores have an increased surface area for cell attachment, infiltration and deployment. ${ }^{2}$ More recently, covalently cross-linked hydrogels such as in situ photocrosslinking and cryogelation have resulted in enhanced mechanical properties and open pore

\footnotetext{
'Tissue Engineering and Regenerative Medicine, Northwick Park Institute for Medical Research (NPIMR), Harrow, UK

${ }^{2}$ Department of Materials Science, Engineering, Institute of Biomaterials, University of Erlangen-Nuremberg, Erlangen, Germany

${ }^{3}$ Antigen Presentation Research Group, Imperial College London, London, UK

${ }^{4}$ Nuffield Department of Surgical Sciences, Oxford Transplant Centre, University of Oxford, Oxford, UK
}

\section{Corresponding author:}

Tahera Ansari, NPIMR, Block Y level 3 Watford Rd, Harrow, UK. Email: t.ansari@NPIMR.org 
architecture, with tissue-like elasticity providing an ideal micro-environment for cell attachment. ${ }^{2}$

In order to develop biomimetic hydrogels, the extracellular matrix (ECM) of specific tissues could be utilised as a starting material. ECM is the non-cellular component present within all tissues and organs and provides the necessary cues required for tissue morphogenesis and differentiation. ${ }^{3,4}$ By incorporating ECM into the fabricated material, the outcome would be a tissue-like architecture and an interface for cells attachment and differentiation with the ability to induce desired biological processes.

3D ECM systems are known to recapitulate many of the in vivo functions such as the physical and mechanical conditions that closely resemble the in vivo environment. ${ }^{5}$ This has led to a number of ECM-based biomaterials such as collagen-based gels, fibrin-based gels and small intestine submucosa exploited in tissue engineering and regenerative medicine. ${ }^{6}$ Although these ECM-based gels have been used to study cell migration, and angiogenesis, they fail to reconstruct the physical state of the native tissue's ECM. For example, matrigel although rich in laminin (an essential adhesion protein), is only expressed in one isoform which is not expressed in mature organs. ${ }^{6,7}$ Another inherent problem is the ECM rigidity. For example, fibrin gels have had some success in tissue engineering but they lack the mechanical strength and durability. Collagen gels can also be heterogeneous and change to their organization and pore size can negatively impact on the architecture. ${ }^{3,7,8}$

Decellularised tissues have been used to reconstitute normal tissues with reasonable fidelity. Glycoproteins and proteins isolated from the decellularised soft tissue have been developed into 3D nanostructure gels with a fibrous network to support integrin-mediated cell growth and endothelial cell differentiation. ${ }^{6}$ The fibrous architecture of the decellularised ECM gels is similar in scale and architecture to the basement membrane in vivo. However, both the structural and protein integrity of the gels are affected by the low acidic $\mathrm{pH}$ during gelation which affects solubility of the proteins and the structural integrity of the subsequent ECM gels. ${ }^{6}$

Many synthetic materials such as functionalised polyacrylamide gels and polyethylene glycol (PEG) hydrogels have been crosslinked with reconstituted basement membrane proteins and have been used as matrices to support cell adhesion, viability and growth. ${ }^{9,10}$ However, some of these hydrogels have been unable to mimic the organizational features of native collagen gels, sometimes impeding cell migration. ${ }^{11}$ Alginate is a natural polysaccharide polymer; both covalent and ionic crosslinking have been used to produce $3 \mathrm{D}$ constructs with cells and is therefore considered biocompatible. ${ }^{1}$ Although the micro and nanostructures of the alginate hydrogels are crosslinked, it does not necessarily produce a tough hydrogel. Therefore, other interpenetrating and double networks of polymer hydrogels have to be included to synthesise tough hydrogels. ${ }^{12}$ Synthetic biodegradable polymers with desired material properties can be obtained by varying their chemical composition. For example, polyvinyl alcohol (PVA) can be easily modified through its hydroxylic groups and since these polymers are FDA approved, they are often considered for material synthesis with improved properties. ${ }^{13}$ However, these polymers are usually biologically inert without any functionality, so have to be combined with natural polymers or biological tissue.

The main objective of this study was to develop a hydrogel composed of a bioactive component (decellularised cartilage) with enhanced mechanical properties (combination of synthetic PVA and natural alginate polymer). It was hypothesised that this hybrid hydrogel would exhibit enhanced structural integrity and biocompatibility.

The decellularised cartilage was produced using mild salt and enzyme solutions and cryomilled into a paste rather than being purified into a solution, thereby retaining protein integrity. Alginate and PVA were functionalized with methacrylate and combined with the decellularised tissue. This was followed by a polymerization reaction in the presence of an initiator to induce fluid to solid phase transformation. The hydrogel was characterised for its physicochemical properties (NMR), biocompatibility (in vitro tests), in vitro molecular weight loss (using gel permeation chromatography (GPC), as well as mechanical properties (compression tests). Proteomics was used to assess the impact of decellularisation on the retained ECM composition.

\section{Materials and methods}

All chemicals and reagents were purchased from Sigma-Aldrich Ltd unless otherwise stated.

\section{Tissue samples}

Fresh auricular cartilage was obtained from LargeWhite/Landrace crossbreed pigs -approx. weight $50 \mathrm{~kg}$ (terminated from unrelated studies at NPIMR) after euthanasia in a clean environment. Cartilage was dissected from the ear, washed with PBS containing antibiotic/anti-mycotic solution (AA) and placed in a freezer at $-20^{\circ} \mathrm{C}$ for at least $24 \mathrm{~h}$. Samples were thawed at room temperature $(\mathrm{RT})$, cut into small pieces $(1 \times 1$ $\mathrm{cm}$ ) in readiness for decellularisation. 


\section{Decellularisation of cartilage samples}

Decellularisation of cartilage samples (10 pieces of $1 \times 1 \mathrm{~cm}$, weighing roughly $500 \mathrm{mg}$ each) was done using osmotic shock, with different enzymatic steps to test for a better preservation of the ECM. The whole process was done at $4{ }^{\circ} \mathrm{C}$ (unless otherwise stated) on a shaking platform set at $60 \mathrm{r} / \mathrm{min}$. Each protocol step lasted $24 \mathrm{~h}$. Samples $(n=16)$ were initially washed in 50 $\mathrm{mL}$ distilled water followed by immersion in a $50 \mathrm{~mL}$ hypertonic solution (10 mM Tris HCL, $5 \mathrm{mM}$ EDTA), followed by immersion into a $50 \mathrm{~mL}$ wash buffer (phosphate-buffered saline; PBS containing $0.05 \%$ Tween-20). Samples were then transferred into a 50 $\mathrm{mL}$ hypotonic solution $(10 \mathrm{mM}$ Tris HCL, $5 \mathrm{mM}$ EDTA) followed by another wash step. On completion, samples were transferred into a $50 \mathrm{~mL}$ incubation buffer $(400 \mathrm{mM}$ Tris $\mathrm{HCl}, 100 \mathrm{mM} \mathrm{NaCl}, 50 \mathrm{mM}$ $\mathrm{MgCl}_{2}, 10 \mathrm{mM} \mathrm{CaCl}$ ) and placed at $37^{\circ} \mathrm{C}$. However, the incubation buffer was supplemented to represent four different conditions ( $n=4$ per condition): condition 1: no enzymes; condition 2: DNAse $(400 \mathrm{kU} / \mathrm{mL})$ and RNase $(140 \mathrm{kU} / \mathrm{mL})$; condition 3: DNAse (100 $\mathrm{kU} / \mathrm{mL})$ and RNase $(140 \mathrm{kU} / \mathrm{mL})$ and condition 4 : Benzonase ${ }^{\circledR}$ Nuclease $250 \mathrm{kU} / \mathrm{mL}$ (Merck Millipore, Nottingham; UK). The final step consisted of another immersion in the wash buffer.

\section{Structural assessment of decellularised samples}

Samples from each condition and controls were fixed for $24 \mathrm{~h}$ in $10 \% \mathrm{NBF}$ (neutral-buffered formalin) solution at RT. Each scaffold was processed for paraffin embedding using routine laboratory techniques. Fivemicron sections were cut and stained with haematoxylin and eosin (H\&E) to evaluate the presence of cells and with Picro-sirius red (PSR-ME) with Milers elastin to assess both the collagen, and elastin content and structural integrity.

\section{Immunohistochemistry using alpha-galactosidase to assess potential immunogenicity}

Paraffin sections $(5 \mu \mathrm{m})$ were cut and mounted on to 2\% (3-aminopropyl) triethoxysilane (APTS) coated slides. Endogenous peroxidase was blocked by incubation with $3 \%$ hydrogen peroxide in methanol for 30 min at RT followed by antigen retrieval (Proteinase $\mathrm{K}$ for $1 \mathrm{~min}$ ). Non-specific binding sites were blocked with Dako protein block (Dako Cambridgeshire, UK) at RT for $30 \mathrm{~min}$. Sections were incubated with the monoclonal primary antibody (anti-alpha galactosidase produced in mouse; Clone MY-32, M4276, Sigma-Aldrich) for $2 \mathrm{~h}$, at a 1:50 dilution in PBS.
After washing with PBS, sections were exposed to the secondary antibody (ImmPress anti-mouse IgG peroxidase kit, Vector Laboratories Ltd, Peterborough, UK) for $30 \mathrm{~min}$. Following washing, a subsequent reaction was carried out with the chromogenic substrate $3,3^{\prime}$ diaminobenzidine (Immpact DAB peroxidase substrate, Vector Laboratories Ltd) for $30 \mathrm{~s}$. For negative controls, primary antibody was substituted with PBS and porcine epithelial cells and cartilage used as positive controls.

\section{Ultrastructural assessment of cartilage samples}

\section{Transmission electron microscopy}

Samples were fixed in 4\% (v/v) glutaraldehyde (Agar Scientific Ltd, Stansted, UK) in $0.1 \mathrm{M}$ phosphate buffer and left for $24 \mathrm{~h}$ at $4^{\circ} \mathrm{C}$. After washing in 0.1 $\mathrm{M}$ phosphate buffer ( $\mathrm{pH}$ 7.4), samples were fixed in $1 \%$ $\mathrm{OsO}_{4} / 0.1 \mathrm{M}$ phosphate buffer $(\mathrm{pH} 7.3)$ at $4^{\circ} \mathrm{C}$ for 1.5 $\mathrm{h}$ and then washed again in $0.1 \mathrm{M}$ phosphate buffer ( $\mathrm{pH}$ 7.4). Samples were stained en bloc with $0.5 \%$ uranyl acetate in distilled water $\left(\mathrm{dH}_{2} \mathrm{O}\right)$ at $4{ }^{\circ} \mathrm{C}$ for 30 min, rinsed with $\mathrm{dH}_{2} \mathrm{O}$, dehydrated in a graded ethanol-water series and infiltrated with Agar 100 resin and then hardened. Sections measuring $1 \mu \mathrm{m}$ were cut and stained with $1 \%$ toluidine blue in $\mathrm{dH}_{2} \mathrm{O}$ for light microscopy. A representative area was selected and sections were cut at $70-80 \mathrm{~nm}$ using a diamond knife on a Reichert Ultracut E microtome. Sections were collected on a 200-mesh copper, coated slot grid and stained with uranyl acetate and lead citrate. Images were recorded with a Jeol 1010 transmission electron microscope and captured with a Gatan digital camera.

\section{Scanning electron microscopy}

Samples were fixed in 4\% (v/v) glutaraldehyde (Agar Scientific Ltd., Stansted, UK) in $0.1 \mathrm{M}$ phosphate buffer and left for $24 \mathrm{~h}$ at $4^{\circ} \mathrm{C}$. Following washing with $0.1 \mathrm{M}$ phosphate buffer, the specimens were cryo-protected in $25 \%$ sucrose, $10 \%$ glycerol in PBS ( $\mathrm{pH}$ 7.4) for $2 \mathrm{~h}$, then fast frozen in liquid nitrogen slush and fractured at approximately $-160^{\circ} \mathrm{C}$. Samples were then placed back into cryo-protectant at room temperature and allowed to thaw. After washing in $0.1 \mathrm{M}$ phosphate buffer ( $\mathrm{pH} 7.4$ ), the material was fixed in $1 \% \mathrm{OsO}_{4} / 0.1 \mathrm{M}$ phosphate buffer $(\mathrm{pH} 7.3)$ at $4^{\circ} \mathrm{C}$ for $1 \frac{1}{2} \mathrm{~h}$ and washed again in $0.1 \mathrm{M}$ phosphate buffer ( $\mathrm{pH}$ 7.4). After rinsing with $\mathrm{dH}_{2} \mathrm{O}$, specimens were dehydrated in a graded ethanol-water series to $100 \%$ ethanol; critical point dried using $\mathrm{CO}_{2}$ and finally mounted on aluminum stubs using sticky carbon tabs. The fractured material was mounted to present 
fractured surfaces to the beam and then coated with a thin layer of $\mathrm{Au} / \mathrm{Pd}$ (approximately $2 \mathrm{~nm}$ thick) using a Gatan ion beam coater. Images were recorded with a Jeol 7401F field emission scanning electron microscope and captured with Jeol software.

\section{Molecular analysis}

\section{DNA quantification assay}

DNA was extracted from the control and Dc cartilage samples using the GenElute Mammalian Genomic DNA Miniprep Kit (Sigma-Aldrich), as per the manufacturers' instructions. In brief, $25 \mathrm{mg}$ of minced wet tissue was placed in a microcentrifuge tube containing Proteinase $\mathrm{K}$ and placed in a water bath set at $55^{\circ} \mathrm{C}$ for $4 \mathrm{~h}$ with regular vortexing at $30 \mathrm{~min}$ to 1 -h intervals. Following complete digestion, the samples were incubated with RNase solution at RT for 2 min. Samples were incubated with lysis reagents from the DNA extraction assay kit and incubated at $70^{\circ} \mathrm{C}$ for 10 min. Columns were then prepared for binding DNA and the lysate loaded. The DNA was subsequently washed to remove contaminants and finally eluted in $200 \mu \mathrm{L}$ of a Tris-EDTA solution. After blanking with elution buffer alone, the absorbances at $260 \mathrm{~nm}$ and $280 \mathrm{~nm}$ were measured to determine the purity and yield of DNA, using a self-masking quartz microcuvette and a spectrophotometer (Helios Alpha; Thermo Fisher Scientific). All experiments were conducted in triplicate. Samples were diluted, where necessary, in order to obtain an absorbance reading between 0.1 and 1.0. From the absorbance readings, the absolute amount of DNA per mg of tissue was calculated.

\section{Agarose gel electrophoresis for DNA base pair length}

To assess for DNA size in the matrices, cartilage samples were cut into small pieces, weighed $(25 \mathrm{mg})$, minced and aseptically kept in DNA-free tubes. DNA was extracted following manufacturer's instructions of GenElute mammalian genomic DNA miniprep kit (Sigma-Aldrich, UK). Total DNA was quantitated by measuring the absorbance in a nano-drop spectrophotometer (NanoDrop ND1000, Thermo Scientific, Wilmington, USA), and the absolute amount of DNA per milligram of tissue was calculated. The size, quality and purity of the extracted DNA were determined by agarose gel electrophoresis. A $1.2 \%$ agarose (Agarose Type I, low EEO; SigmaAldrich, Dorset, UK) gel with $1 \times$ Tris-borateethylenediaminetetraacetic acid (TBE - Bio Reagent, $10 \times$, Sigma-Aldrich, UK) running buffer was run at 4 to $5 \mathrm{~V} / \mathrm{cm}$ between the electrodes. Equal volumes of DNA $(5 \mu \mathrm{L})$ mixed with $1 \mu \mathrm{L}$ of loading buffer
(5× DNA loading buffer, Yorkshire Bioscience Ltd., York, UK) were loaded into each well. Visualization was achieved by staining with $1 \%$ of ethidium bromide and DNA was measured via ultraviolet transillumination against a 1-kb DNA ladder (Q-Step 4 quantitative DNA ladder, Yorkshire Bioscience Ltd, York, UK).

\section{Proteoglycan and core protein extraction}

The frozen samples of cartilage were homogenized (Precellys 24, Stretton Scientific Ltd, UK) in $1 \mathrm{~mL}$ of extraction buffer (4 M guanidine hydrochloride $(\mathrm{GuHCl}), 0.05 \mathrm{M}$ sodium acetate $(\mathrm{pH} 6.0)$ and $2 \%$ Triton X-100), with $12 \mu \mathrm{L}$ of protease inhibitors (1 mM PMSF, $10 \mathrm{mM}$ N-ethylmaleimide, $10 \mathrm{mM}$ EDTA) and left to agitate for $18 \mathrm{~h}$ at $4^{\circ} \mathrm{C}$. The ratio to the tissue to the extraction buffer was 1:20. After 18 $\mathrm{h}$, the lysed sample was centrifuged (Prism R, Labnet International UK) for $10 \mathrm{~min}$ at $12,000 \mathrm{r} / \mathrm{min}$ to pellet the tissue debris. The protein containing supernatant was transferred to an eppendorf to which $20 \mu \mathrm{L}$ of RNAse enzyme $(140 \mathrm{KU} / \mathrm{mL})$ was added and allowed to incubate for $2 \mathrm{~min}$ at RT. Fourteen microliters of the DNAse reaction buffer $(50 \mathrm{mM}$ Tris $\mathrm{HCl}, 10 \mathrm{mM}$ $\mathrm{MgCl}_{2}$, and $0.1 \mathrm{mM} \mathrm{CaCl}$ ) were added to the supernatant and mixed well which was followed by the addition of $5 \mu \mathrm{L}$ of DNAse I enzyme $(100 \mathrm{KU} / \mathrm{mL})$. The solutions were gently agitated without vortexing. The supernatant was then incubated at $37^{\circ} \mathrm{C}$ for $30-60 \mathrm{~min}$ till the viscosity of the supernatant was reduced. The supernatants were transferred to a dialyzer $(\mathrm{MWCO}=3.5 \mathrm{kDa})$ and dialyzed against distilled water for $24 \mathrm{~h}$ at $4{ }^{\circ} \mathrm{C}$. Dialysis was continued until the buffer exchange reached equilibrium (approximately 2-4 h) then fresh dialysis buffer was replaced and the process was repeated. By using $2 \times 500$ volume of dialysis buffer, the final concentration of $\mathrm{GuHCl}$ in the sample was reduced to $16 \mu \mathrm{M}$; this concentration of $\mathrm{GuHCl}$ is known not to interfere with the dye binding assay or SDS-PAGE.

\section{Protein precipitation from the supernatant was carried out using either ethanol or PCIA}

\section{Samples treated with ethanol}

After dialysis, $1 \mathrm{~mL}$ of ice cold ethanol was added to supernatant to allow the protein to precipitate. The samples were placed at $4^{\circ} \mathrm{C}$ for $24 \mathrm{~h}$ and then centrifuged at $12,000 \mathrm{r} / \mathrm{min}$ for $10 \mathrm{~min}$ at $4^{\circ} \mathrm{C}$. The pellet was solubilised with ultrapure water. 


\section{Samples treated with PCIA}

After dialysis, $50 \mu \mathrm{L}$ of Tris base (pH 9.5) was added to the supernatant after which two volumes of ice cold phenol-chloroform-isoamyl alcohol (PCIA) or 70\% ethanol was added. This solution was allowed to stand for $24 \mathrm{~h}$ at $4^{\circ} \mathrm{C}$. For the samples that were treated with PCIA, the protein was allowed to precipitate at the interface. The DNA/RNA present in the upper aqueous layer was removed, and similarly the lower organic layer containing the solvents was also removed. The protein layer at the interface was carefully removed and transferred to another microcentrifuge. The protein was precipitated using ice cold ethanol and centrifuged at 12,000 $\mathrm{r} / \mathrm{min}$ at $4^{\circ} \mathrm{C}$ for $10 \mathrm{~min}$. The pellet was washed with ice cold ethanol twice and solubilised with ultrapure water for subsequent analysis.

\section{Sulfated-glycosaminoglycan assay}

The Blyscan GAG assay kit (Biocolor, Carrickfergus, Northern Ireland) was used to quantify sulphated glycosaminoglycan (sGAG) using the pellet obtained from the PCIA extraction method. Each pellet was solubilised in $100 \mu \mathrm{L}$ of deionised water. The standards were set up using aliquots containing 1.0, 2.0, 3.0, 4.0 and $5.0 \mu \mathrm{g}$ of the reference standard. The final volume was made up to $100 \mu \mathrm{L} ; 50 \mu \mathrm{L}$ of each sample solution was pipetted into new microcentrifuge tubes and $1 \mathrm{~mL}$ Blyscan dye reagent was added. The tubes were mixed by inversion and then placed in a gentle mechanical shaker for $30 \mathrm{~min}$. sGAG-dye complex was formed which precipitates out from the soluble unbound dye. The tubes were then centrifuged at $12,000 \mathrm{r} / \mathrm{min}$ for 10 min. The fluid from the tubes was carefully drained leaving just the dye-sGAG complex pellet at the bottom of the tube. To this, $0.5 \mathrm{~mL}$ of dissociation reagent was added and the tubes were re-caped and the bound dye was released into the solution using a vortex mixer. Once released, within $10 \mathrm{~min}$ the samples were ready for measurement; $50 \mu \mathrm{L}$ of each sample was added to a microcuvette and read at a wavelength of $656 \mathrm{~nm}$ using a spectrophotometer (Helios Alpha; Thermo Fisher Scientific) and compared to a plot of standards made from bovine tracheal chondroitin-4sulphate to determine the absolute s-GAG content. The absorbance was measured against water for reagent blanks, standards and test samples. All experiments were performed at least in triplicate.

\section{Collagen extraction assay}

The method used for s-GAG extraction was also used for collagen extraction except that the supernatants were transferred to a dialyzer with a NMWCO $-10,000 \mathrm{Da}$ and dialyzed against distilled water for
$24 \mathrm{~h}$ at $4^{\circ} \mathrm{C}$ with stirring. Dialysis was continued until the buffer exchange reached equilibrium (approximately 2-4 h), then fresh dialysis buffer was replaced and the process was repeated. After dialysis, the supernatant was transferred to an Amicon ultra filter 2 to remove the hydrolysed DNA and salts. The samples were centrifuged (Sorvall Legent RT, Kendro Lab products, Germany) at $5400 \mathrm{r} / \mathrm{min}$ for $30 \mathrm{~min}$. After centrifugation, $50 \mu \mathrm{L}$ of Tris base ( $\mathrm{pH}$ 9.5) was added to the retenate after which one volume of ice cold phenol-chloroform-isoamyl alcohol (PCIA) was added. This solution was allowed to stand for $24 \mathrm{~h}$ at $4^{\circ} \mathrm{C}$ to allow the protein to precipitate at the interface. The DNA/RNA present in the upper aqueous layer was removed, and similarly the lower organic layer containing the solvents was also removed. The protein layer at the interface was carefully removed and transferred to another micro centrifuge tube. The protein was precipitated using ice cold acetone and centrifuged at $12,000 \mathrm{r} / \mathrm{min}$ at $4^{\circ} \mathrm{C}$ for $10 \mathrm{~min}$. The pellet was washed with ice cold ethanol twice and solubilised with ultrapure water.

\section{Collagen quantification assay}

Collagen was quantified using Sircol collagen assay kit (Biocolor, Carrickfergus, Northern Ireland). Briefly, $100 \mu \mathrm{L}$ of distilled water was add to each sample $(n=3)$ to solubilise the pellet and this volume was subjected to the Sirius red dye binding, followed by wash with ice-cold acid-salt reagent to remove the unbound dye. Samples were centrifuged and the dye bound to collagen was released from the pellet with alkali reagent $(1 \mathrm{~N} \mathrm{NaOH})$. Extracts were placed in a 96-well plate in triplicates and spectrophotometric readings were taken at $555 \mathrm{~nm}$ on a microplate reader (Versamax, Molecular Devices LLC, USA). Absolute values were attained with a standard curve composed of type I bovine skin collagen solution $(0.5 \mathrm{mg} / \mathrm{mL})$ in the range of 5-100 $\mu \mathrm{g}$ per $0.1 \mathrm{~mL}$. Total collagen was normalized per milligram of tissue. Samples were then run on SDS-PAGE for collagen type. Briefly, $10 \mu \mathrm{l}$ of each sample was separated using gradient pre-cast $4-15 \%$ polyacrylamide gels of $1 \mathrm{~mm}$ thickness (MiniPROTEAN TGX Stain-Free Precast Gel, Bio-Rad Laboratories Inc., USA) and run with the gel system apparatus (Mini- PROTEAN Tetra System, Bio-Rad Laboratories Inc., USA) at $100 \mathrm{~V}$ for $2 \mathrm{~h}$. Dual colour protein markers (10 kDa-250 kDa) Precision plus Protein $^{\mathrm{TM}}$ standards (BioRad, Hertfordshire, UK) were used. Protein bands on gel were stained with Coomassie blue (Coomassie blue R350, Invitrogen, UK) and allowed to de-stain in water for 24-28 h. Images were taken to qualitatively assess the protein fractions compared to control samples. 


\section{Protein extraction for proteomic analysis}

Cartilage samples were homogenised on a beads beater at $6500 \mathrm{r} / \mathrm{min}$ for $45 \mathrm{~s}$ with the addition of lysis buffer $(8$ M urea, $50 \mathrm{mM}$ Tris-HCL, pH 8.5, $5 \mathrm{mM}$ DTT, $1 \%$ SDS, and protease inhibitor) to obtain a final concentration of $20 \mathrm{mg} / \mathrm{ml}$. The samples were homogenized again with a bead beater (Precellys ${ }^{\circledR}$ evolution, Stretton Scientific LTD, UK) at $6500 \mathrm{r} / \mathrm{min}$ for $45 \mathrm{~s}$ and repeated for four times in total. The samples were centrifuged at $12,000 \mathrm{r} / \mathrm{min}$ for $5 \mathrm{~min}$ at $4^{\circ} \mathrm{C}$. The supernatant was collected and protein concentration was determined by a BCA assay (Thermo, UK) and $100 \mathrm{ug}$ of total proteins were added to a $30 \mathrm{kDa}$ filter (Millipore, UK). Proteins were reduced by $20 \mathrm{mM}$ DTT (Sigma, UK) at $37^{\circ} \mathrm{C}$ for $1 \mathrm{~h}$, and then alkylated with $100 \mathrm{mM}$ iodoacetamide (IAA, Sigma, UK) for 45 min in the dark, at RT. Samples were centrifuged for 20 $\mathrm{min}$ at $12,000 \mathrm{r} / \mathrm{min}$ to remove DTT and IAA and followed by buffer exchange with $8 \mathrm{M}$ urea once and 50 $\mathrm{mM} \mathrm{NH} \mathrm{HCO}_{3}$ for three times. One hundred microliter of trypsin was added at a trypsin/protein ratio of 1:50 for digestion at $37^{\circ} \mathrm{C}$ overnight. Digested peptides were collected by upside down spin and washed twice with 0.5 $\mathrm{M} \mathrm{NaCL}$ and water, respectively. The peptides were purified by SepPak C18 cartridge (Waters, UK), dried in a SpeedVac and re-suspended in buffer $(2 \%$ acetonitrile $0.1 \%$ formic acid) and then used for LC-MS/MS.

\section{Protein identification and quantitation by mass spectrometry}

LC-MS/MS analysis was carried out using nano-ultra performance liquid chromatography tandem MS using a $75 \mu \mathrm{m}$-inner diameter $\times 25 \mathrm{~cm} \mathrm{C} 18$ nanoAcquity ${ }^{\mathrm{TM}}$ UPLC $^{\mathrm{TM}}$ column (1.7- $\mu \mathrm{m}$ particle size, Waters). Peptides were separated with a 120 min gradient of 3-40\% solvent B (solvent A:99.9\% $\quad \mathrm{H}_{2} \mathrm{O}, \quad 0.1 \%$ formic acid; solvent B: $99.9 \%$ ACN, 0.1\% Formic acid) at $250 \mathrm{nl} / \mathrm{min}$ and injected into a LTQ Orbitrap Velos (Thermo Scientific) acquiring data in positive ion mode. The MS survey was set with a resolution of 30,000 FWHM with a recording window between 300 and $2000 \mathrm{~m} / \mathrm{z}$, a maximum acquisition time of $100 \mathrm{~ms}$ and the automatic gain control target set to $1,000,000$ ions. Minimum MS signal for triggering MS/MS was set to $500, \mathrm{~m} / \mathrm{z}$ values triggering MS/MS were put on a dynamic exclusion list (500 entries), and exclusion duration as $30 \mathrm{~s}$. A maximum of $20 \mathrm{MS} / \mathrm{MS}$ scans were triggered per MS scan. The lock mass option was enabled and polysiloxane (m/z 371.10124) was used for internal recalibration of the mass spectra. All samples were measured with the MS setting charge state rejection enabled and only more than one charge procures ions selected for fragmentation.

\section{Analysis of mass spectrometry data}

Raw LC-MS/MS data from different samples were converted to MGF file using MS Concert software (ProteoWizard). MGF files were then uploaded to inhouse Central Proteome Facility Pipeline (CPFP) software for protein identification and quantitation. Three search engines including Mascot, OMSSA, and X! Tandem were used for protein identification that were combined with iProphet, with a calculated false discovery rate (FDR) of $1 \%$.

\section{Hybrid bioactive hydrogel synthesis}

Alginate and PVA methylacrylate (MA) hydrogel was prepared by dissolving sodium alginate $(1 \mathrm{~g})$ and PVA $(1 \mathrm{~g})$ in a solution containing $0.5 \mathrm{M} \mathrm{NaCl}(\mathrm{pH} 6.5)$ and $50 \mathrm{mM}$ MES buffer (2-(N-Morpholino) ethanesulfonic acid hydrate), $2.6 \mathrm{~g}$ of NHS (N-Hydroxysuccinimide) and $5.6 \mathrm{~g}$ of EDC (N-Ethyl-N'-(3-dimethylaminopropyl) carbodiimide hydrochloride), in order to activate the carboxylic groups in the alginate. After $5 \mathrm{~min}$, $4.48 \mathrm{~g}$ of 2-aminoethylmathacrylate (AEMA) was added to the solution and agitated $(12,000 \mathrm{r} / \mathrm{min})$ at RT for $24 \mathrm{~h}$. The mixture was twice precipitated in acetone. The precipitate was then collected in distilled water and stored at $4^{\circ} \mathrm{C}$ until further use. Following precipitation of the MA-PVA and alginate mixture, Dc tissue (produced under condition 3) was mixed with MA-PVA and alginate mixture at a ratio of 3:1. Prior to mixing, the De tissue was milled into a powder (Spex SamplePrep Cryomill, Stanmore, UK) using 1 operating cycle at an impaction rate of $15 \mathrm{cps}$, with a run time of $2 \mathrm{~min}$ and a cool time of $1 \mathrm{~min}$. This mixture was polymerised by the addition of tetramethylethylenediamine (TEMED) $\quad(0.5 \% \quad$ (wt./vol)] and ammonium persulfate (APS) $[0.25 \% \quad$ (wt./vol)); to reduce the rate of polymerization, small amount $(0.25 \%)$ of initiator was used. After polymerization, gels were incubated at RT and dialysed with water to remove any unreacted polymeric precursors. The samples were placed in a $-80^{\circ} \mathrm{C}$ freezer for $24 \mathrm{~h}$ followed by direct transfer to $30^{\circ} \mathrm{C}$ (i.e. samples were not allowed to thaw out) for a further seven days.

\section{Characterization of the hybrid hydrogel}

\section{High-resolution IH nuclear magnetic resonance spectra}

High-resolution solid state HNMR spectra were observed in deuterium oxide $\left(\mathrm{D}_{2} \mathrm{O}\right)$ using a Varian Unity-300 (300 MHz) NMR spectrometer (Varian). To analyse the methacrylation efficiency, 1H NMR spectra were recorded for methacrylated alginate and 
PVA. 1H NMR spectroscopy was also used to characterize vinyl group conversion after polymerization both with and without Dc tissue.

\section{GPC}

In order to assess the degradation rate of the bioactive hydrogel samples, with and without Dc tissue, $1 \mathrm{~cm}$ discs were immersed in $1.5 \mathrm{~mL}$ simulated body fluid (SBF) ${ }^{14}$ for a period of 30 days at $37^{\circ} \mathrm{C}$. Samples ( $n=3$ for each time point per group) were incubated for 1,14 , and 30 days before being subjected to GPC analysis. Molecular weight averages and polydispersity index (PDi) were calculated using a poly(ethylene glycol) (PEG) calibration. The samples were made up to a 50/50 volume concentration in aqueous eluent and left for $4 \mathrm{~h}$ to solubilise prior to filtration through a 0.2 $\mu \mathrm{m}$ filter. All GPC data were recorded on an Agilent Technologies Infinity 1260 instrument equipped with a differential refractive index (DRI) detector. Samples were run on an $8 \mu$ PL aquagel-OH 30 column and an $8 \mu \mathrm{PL}$ aquagel-OH $40(300 \times 7.5 \mathrm{~mm})$ column $(300 \times 7.5 \mathrm{~mm})$, with two $8 \mu \mathrm{PL}$ aquagel guard columns (pre and post separating columns). The mobile phase used was $0.1 \mathrm{M}$ sodium nitrate $\mathrm{NaNO}_{3}$ solution.

\section{Mechanical assessment}

Hydrogels with and without Dc cartilage ( $n=7$ each) were axially compressed at a strain rate of $1 \% / \mathrm{s}$ at $23^{\circ} \mathrm{C}$. with an Instron model 5967 (Instron, Buckinghamshire, UK) equipped with a $1000 \mathrm{~N}$ load cell; prior to compression sampling, the dimension was measured using a calliper (0.01 $\mathrm{mm}$ precision) - the average sample size was $17 \mathrm{~mm}$ in diameter and $12 \mathrm{~mm}$ in height. The compressive modulus was calculated to determine the effect of fatigue on the stiffness of the hydrogels. The modulus was calculated automatically by the software (Bluehill 3, Instron, Buckinghamshire, UK) by intercepting the best line in the linear region of the curve. The Poisson's ratio was calculated based on the change of diameter between different strains (the negative of the ratio of (signed) transverse strain to (signed) axial strain).

\section{In vitro biocompatibility assessment}

\section{Bone-marrow mesenchymal stem cells isolation}

Under anaesthesia and sterile conditions, the hind limb was extended and a $1 \mathrm{~cm}$ transverse cutaneous incision is made medially at the mid-point of the femur and blunt dissection used to locate the femur. Bone marrow aspiration was performed using a heparinised $11 \mathrm{G}$ Jamshidi needle. Aspiration yield varied between 20 and $60 \mathrm{~mL}$ based on the age of the animal. Porcine bone marrow aspirates underwent gradient separation using Histopaque ${ }^{\circledR}$ (Sigma Aldrich, UK) at a 1:1 ratio. Tubes were centrifuged at $400 \mathrm{~g}$ for $40 \mathrm{~min}$ and cellular monolayer carefully extracted before washing in $10 \mathrm{~mL}$ PBS at $250 \mathrm{~g}$ for $10 \mathrm{~min}$. A further two washes in PBS were performed. Pellets were reconstituted in $10 \mathrm{~mL}$ of Alpha Minimum Essential Medium ( $\alpha$ MEM - Sigma Aldrich, UK) and plated into T75 flasks. They were kept in a humidified incubator at $37^{\circ} \mathrm{C}, 5 \% \mathrm{CO}_{2}$ supplemented with $10 \%$ FBS (Hyclone/ThermoScientific, Rockford, MD, USA) and $1 \%$ of AA (growth medium) and allowed to attach. Flasks were reviewed daily and washed after $48 \mathrm{~h}$ to remove unwanted cells and debris. The medium was changed every $48 \mathrm{~h}$. BMMSC reached confluence after approximately 10 days and was split at ratio $1: 2$ using $0.25 \%$ Trypsin- EDTA (Sigma Aldrich, Dorset, UK) and used for seeding the hydrogels.

\section{In vitro co-culture system}

Prior to the in vitro assay, hydrogel with and without Dc tissue were allowed to dry, cut into $1 \times 1 \mathrm{~cm}$ pieces, washed with PBS containing $3 \times$ AA for $24 \mathrm{~h}$ and then incubated in growth medium ( $\alpha$-MEM with $10 \%$ FCS and $1 \% \mathrm{AA}$ ) overnight at $37.5^{\circ} \mathrm{C}$ and $5 \% \quad \mathrm{CO}_{2}$. Hydrogels were placed in a 12-well plate and porcine bone marrow-derived mesenchymal stem cells (BMMSC) were seeded on each sample at $2.5 \times 10^{5}$ cells per $\mathrm{cm}^{2}$ in triplicate. Cells were allowed to adhere for $2 \mathrm{~h}$ and then fresh medium (a-MEM, 10\% FBS and 1\% AA) was added into each well. The medium was changed every other day. After three and seven days in co-culture, hydrogels were collected, gently washed with PBS, fixed in NBF $10 \%$ for $24 \mathrm{~h}$ and processed for histological analysis.

\section{Histological analysis}

Each sample was cut into $1 \mathrm{~mm}$ segments and a representative section cut at $5 \mu \mathrm{m}$ and stained with $\mathrm{H} \& \mathrm{E}$. Additional sections underwent IHC staining with a cell proliferative marker - ki-67. Briefly following rehydration, sections underwent antigen retrieval with $10 \mathrm{mM}$ sodium citrate buffer $\mathrm{pH} 6,99^{\circ} \mathrm{C}$ for $30 \mathrm{~min}$, left to cool for $15 \mathrm{~min}$ at RT, followed by endogenous peroxide block using 3\% hydrogen peroxide for $30 \mathrm{~min}$ followed by a nonspecific block using $2.5 \%$ normal horse serum (Impress Reagent Kit Peroxidase, Peterborough, UK). Sections were incubated with the primary antibody ki-67 - (Monoclonal mouse anti-human clone MIB-1, Dako, Cambridge, UK), 1:50 in PBS for 1.5 $\mathrm{h}$, the secondary antibody (Anti-mouse IgG Impress Reagent Kit Peroxidase Anti-mouse IG, Burlingame, CA, USA) was applied for $30 \mathrm{~min}$ at RT. Finally, the 

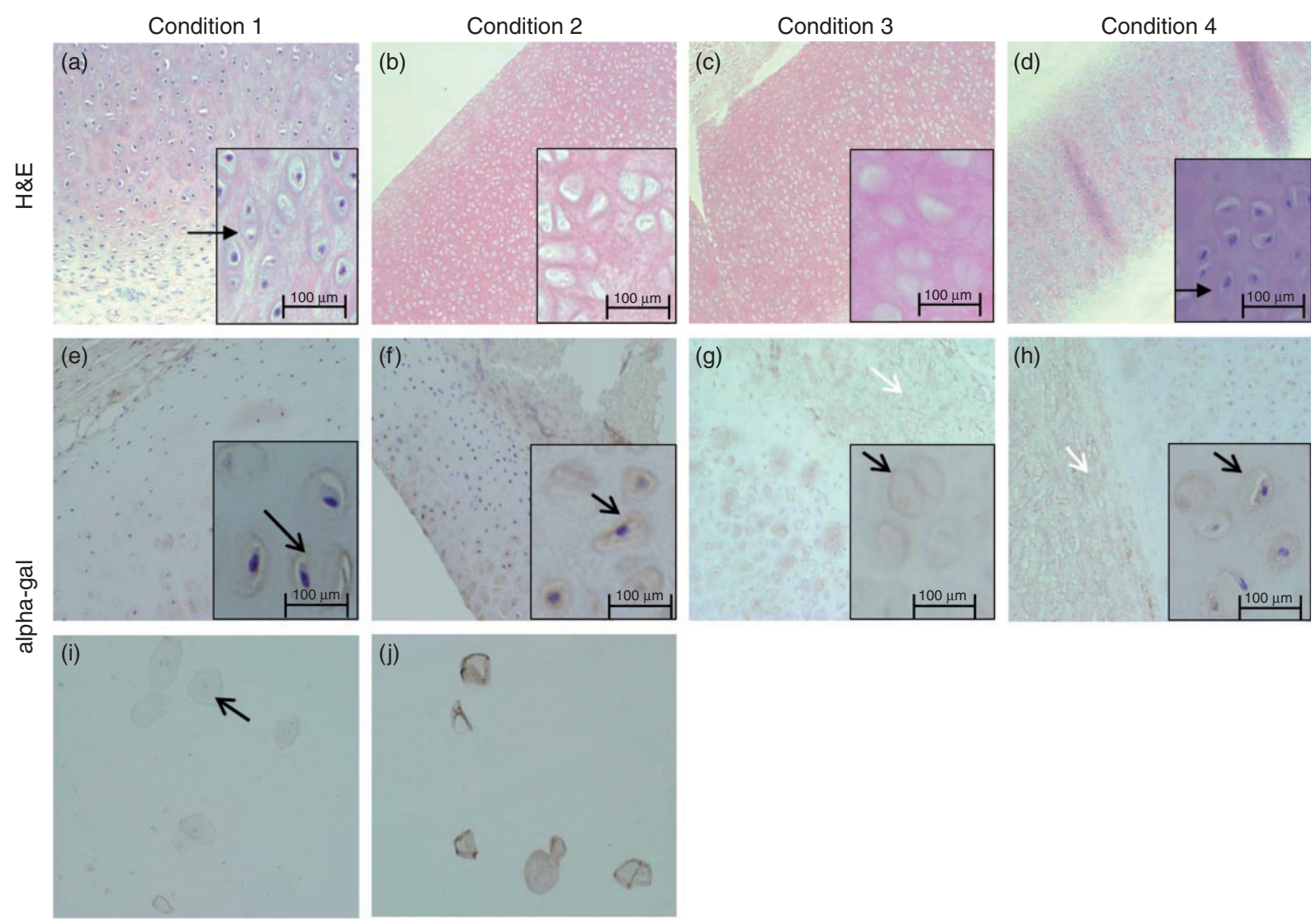

Figure I. Histological assessment of decellularised cartilage samples under different conditions stained with haematoxylin and eosin (H\&E) and alpha-galactosidase (alpha-gal). Following decellularisation, intact cells with nuclei (arrow) are seen in Condition I (a) and Condition 4 (d). Alpha-gal staining in the cytoplasm is indicated by black arrows in conditions I(e), 2(f), 3(g) and 4(h), while white arrows indicate the same staining in the ECM. Porcine cheek epithelial cells were used as a positive control (j). Absence of primary antibody on the same sample was taken as negative control (i).

chromogen was developed using the DAB Peroxidase Kit (Vector Impact DAB peroxidase substrate kit, Peterborough, UK).

\section{Statistical analysis}

Data were calculated as mean \pm standard error, and significance was determined by performing two-tailed Student's $t$-tests or ANOVA (Prism 5: Graphpad Software, La Jolla, CA), followed by Bonferroni as post hoc test. A $p$ value of less than 0.05 was considered to be significant.

\section{Results}

\section{Characterisation of the porcine auricular cartilage scaffolds}

Different Dc protocols were applied to the cartilage samples in order to produce an acellular scaffold. Samples were assessed for the absence or presence of cells and maintenance of ECM (collagen and elastin).
The cartilage tissue treated under condition 1 showed little nuclear clearance with cells clearly identifiable within the cartilage lacunae (Figure 1(a)), those treated in condition 2 (Figure 1(b)) showed clearance of the nuclei but at high power magnification, occasional nucleus outline was still observed. Under condition 3 (Figure 1(c)), there was significant clearance of nuclear material, whereas condition 4 (Figure 1(d)) showed minimal reduction in the nuclear material. This cellular profile was reflected with regard to the amount of DNA retained under each condition when compared to control tissue $(351.46 \mathrm{ng} / \mathrm{mg}$ ); condition 1: $61.6 \mathrm{ng} / \mathrm{mg}$ \pm 0.020 , condition $2: 79.46 \mathrm{ng} / \mathrm{mg} \pm 0.025$; condition 3: $25.33 \mathrm{ng} / \mathrm{mg} \pm 0.020$ and condition $4: 107.47 \mathrm{ng} / \mathrm{mg}$ \pm 0.03 . Samples were also assessed for their potential to elicit an immune response if implanted in vivo by staining for $\alpha$-GAL. Samples with retained cells (intact or partial) showed positive staining within the cytoplasm and on the collagen matrix (Figure 1(e), (f) and (h)). Where no cells were present, positive staining was only seen on the collagen matrix (condition 3 : Figure 1(g)). 

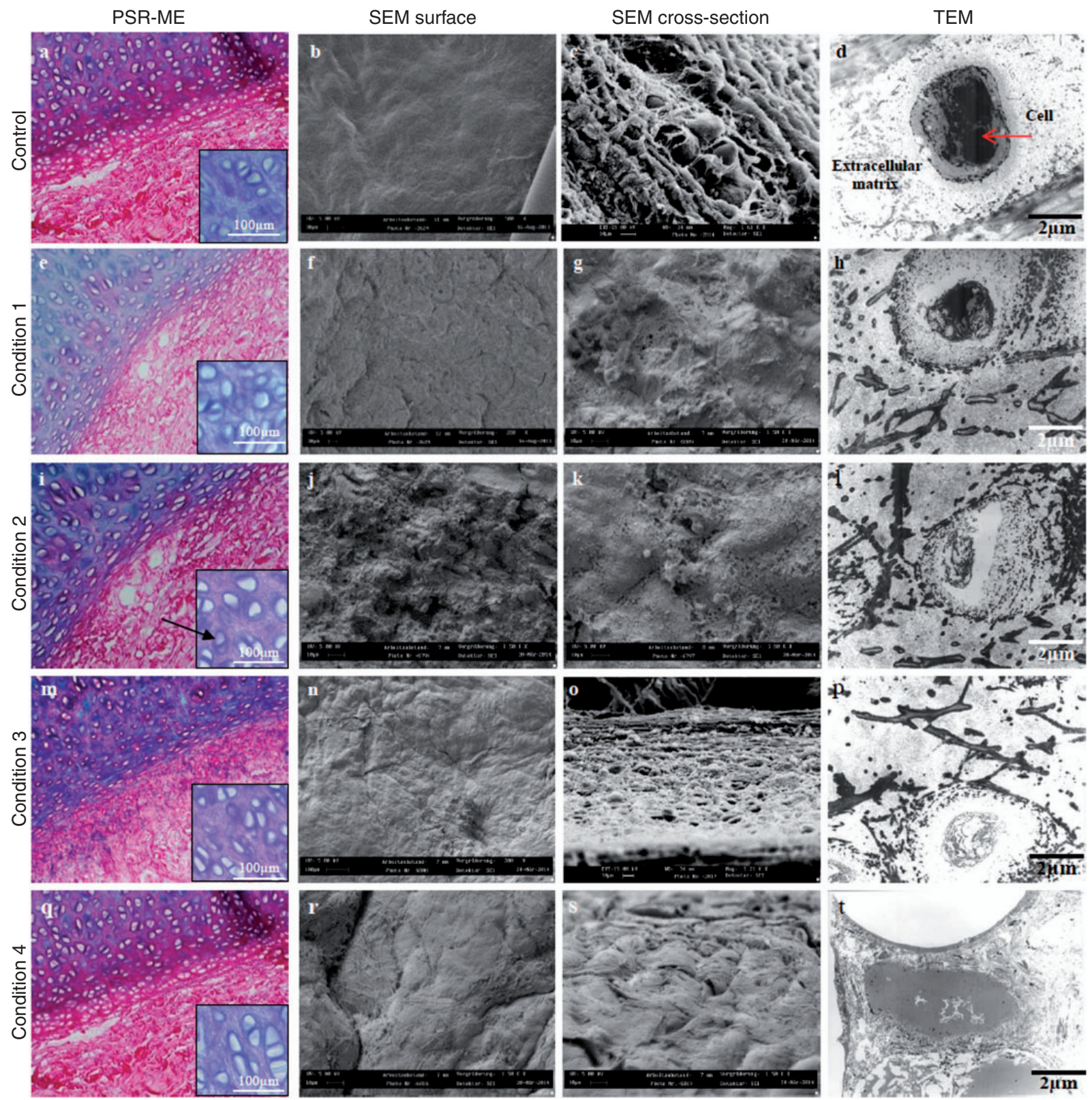

Figure 2. ECM structural integrity. Histological sections stained with Picro-sirius red (PSR; taken under bright field microscopic light) show the presence of the intact collagen fibres stained in red and also the elastin fibres (arrow) stained in blue (Millers elastin staining), noticeable in all conditions tested $(\mathrm{a}, \mathrm{e}, \mathrm{m}, \mathrm{q})$. Scanning electron microscopy (SEM) and transmission (TEM) micrographs of the control (native auricular cartilage) and decellularised scaffolds (Dc).

\section{Structural characterisation}

For all conditions, PSR-ME sections showed good retention of both collagen and fine elastic fibres, which are easily identifiable within the tissue overlying the cartilage and at the edge of the lacunae (Figure 2(a), (e), (i), (m) and (q)). Ultrastructural characterization was performed by SEM and TEM. SEM image of the controls showed a uniform surface topography of the ECM with cells present in the lacunae.
These images were in contrast to the rough surface topography of both the non-enzymatically (condition1: Figure 2(f)) and enzymatically (conditions 2-4 Figure 2 (j), (n) and (r)) treated samples. From the SEM crosssections, the enzymatically treated samples (conditions 2-4 Figure 2(k), (o) and (s)) appeared spongy and porous with empty lacunae confirming the absence of some cells. TEM images of the controls revealed an intact cell surrounded by the ECM (Figure 2(d)). In contrast, all treated samples appeared to have, to 
varying degrees, remnants of nuclei (Figure 2(h), (l), (p) and (t)).

\section{Analysis of the ECM: s-GAGs, collagen and retained proteins}

The ECM components of the Dc samples were assessed via quantification of proteins (using two different methods of precipitation), s-GAGs and collagen quantification, followed by proteomics analysis of the retained proteins and collagens.

Following protein extraction, precipitation was optimized by using ethanol or PCIA. Precipitation by ethanol resulted in faint bands compared to PCIA. In both the ethanol and PCIA precipitated samples, small proteoglycans were observed at $15 \mathrm{kDa}$, whereas the multi-molecular aggregates of high-molecular weight proteoglycans, protein and collagen were observed with a molecular weight range from 100 to $250 \mathrm{kDa}$ (data not shown). The total protein quantification was higher using ethanol compared to PCIA (ethanol $=0.11 \pm 0.01 \mu \mathrm{g} / \mathrm{mL} ; \quad$ PCIA $=0.07 \pm 0.1 \mu \mathrm{g} /$ $\mathrm{mL} ; n=3$ per analysis). During ethanol precipitation, the lipid-rich proteins were probably de-lipidated and precipitated along with nuclei acid, whereas in the PCIA precipitated samples, nucleic acids were absent and therefore the viscosity was reduced allowing for the ease of migration of the protein. In the absence of the nucleic acids and proteins, the amounts of s-GAGs were significantly higher when compared to the ethanol-precipitated samples $(\mathrm{PCIA}=0.64 \pm 1.0 \mu \mathrm{g} /$ $\mathrm{mL}$ and ethanol $=0.54 \pm 0.1 \mu \mathrm{g} / \mathrm{mL}$ ). Therefore, only samples obtained via PCIA precipitation were used in the subsequent analysis.

\section{Sulphated-glycosaminoglycans quantification}

The s-GAG content of the control and the Dc tissue samples were assessed quantitatively using the Blyscan $^{\mathrm{TM}}$ assay kit. The amount of s-GAGs retained in the samples showed $60 \%$ reduction when compared to control tissue $(100 \% ; 0.65 \mu \mathrm{g} / \mathrm{mg} \pm 0.001)$. Amongst the four conditions, condition 1 showed the greatest retention of s-GAG's $(32 \pm 4.8 \% ; 0.23 \mu \mathrm{g} / \mathrm{mg})$ when compared to the enzymatically treated Dc samples (condition 2, condition 3 and condition 4). Amongst the enzymatically treated samples, condition 3 retained the highest percentage of s-GAGs $(28 \pm 1.01 \% ; 0.19$ $\mu \mathrm{g} / \mathrm{mg} \pm 0.001)$ when compared to condition 2 (23 $\pm 1.01 \% ; 0.17 \mu \mathrm{g} / \mathrm{mg} ; \pm 0.001)$ and condition $4(18$ $\pm 0.51 \% ; 0.11 \mu \mathrm{g} / \mathrm{mg} \pm 0.001$ ).

\section{Collagen quantification}

The soluble collagen content of the control and Dc tissue was assessed quantitatively using the Sircol ${ }^{\mathrm{TM}}$ assay kit (Figure 3(a)). The amount of collagen extracted from all the Dc samples decreased significantly when compared to the control tissue. There was no significant difference in collagen retention between the non-enzymatically (condition 1) and enzymatically treated samples (conditions 2-3). Amongst the DNAase/ RNAse enzymatically treated samples, condition 3 retained the highest percentage $(41 \%)$ of collagen. Tissues treated with Benzonase ${ }^{\circledR}$ Nuclease (condition 4) retained $89 \%$ of collagen when compared to the control. One-dimensional SDS-PAGE analysis was used to analyse the collagen tissues from the control and Dc samples (Figure 3(b) and (c)). As expected, the control tissue had a combination of both type I and type II collagens (Figure 3(b)). Collagen extracted from the Dc tissue samples showed similar banding patterns comparable to the control; however, some lower molecular weight collagens were not observed in the gels (Figure 3(c)). SEM images (Figure 3(d) and (e)) showed that condition 3 displayed a compact meshwork of collagen architecture and regular orientation of the fibrils. At higher magnification, these fibrils were aligned in parallel to one another while exhibiting banding along their length.

\section{Proteomics analysis}

Based on the results, condition 3 produced the optimum acellular scaffold while simultaneously retaining the highest amount of ECM components. To further characterise the retained proteins, detailed protein analysis of the ECM composition was performed. A total of 1624 extra cellular proteins were found in the control sample and 1337 in the Dc tissue - representing a $17.6 \%$ loss in in the Dc tissue. Of the 1624 proteins, 1307 were extra cellular proteins and 17 were common proteoglycans (found in both control and Dc tissue). Table 1 lists the common (i.e. present in both $\mathrm{D}$ and control tissue) proteoglycans, collagens, adhesion and anchoring proteins.

\section{Hydrogel analysis}

After polymerization, the vinyl conversion of the MAalginate and PVA macromonomer was characterised using ${ }^{1} \mathrm{H}$ NMR. The characteristic peaks for alginate ( $\delta 3.5$ and $5.0 \mathrm{ppm})$ and for PVA (1.93 ppm) were readily observed (Figure 4(a) and (b)) as was the vinylic peaks for the methyl acrylate $(\delta 5.7$ and $5.8 \mathrm{ppm}$ Figure 4(c)). However, the characteristic vinylic peak ( $\delta 5.7$ and 5.8 ppm:) observed before cross-linking had disappeared (Figure 4(d)) since ammonium persulphate (APS) was used as an initiator and $N, N, N_{-}, N_{-}$TEMED as a catalyst. The absence of the peaks indicated that the polymerization of the MA-alginate and PVA macromonomer had taken place in the presence 
(a)

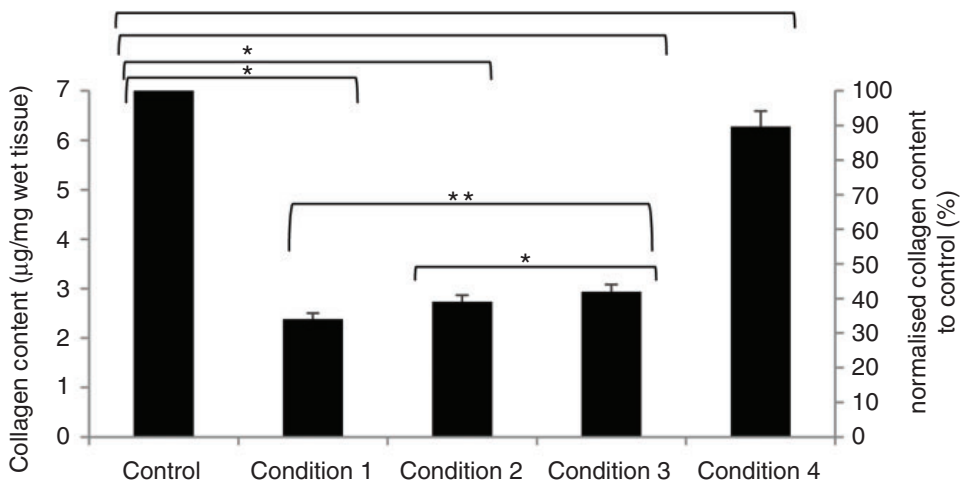

(b)

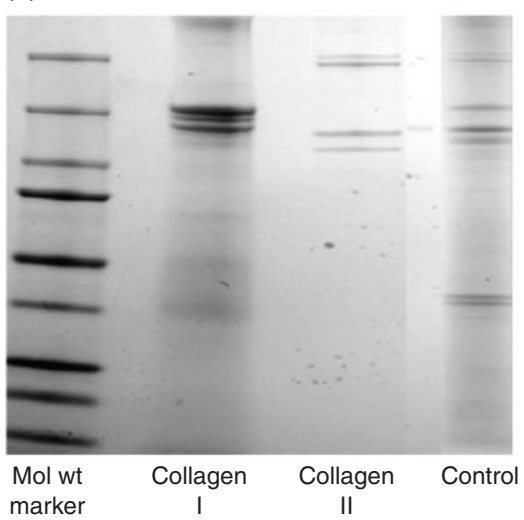

(c)

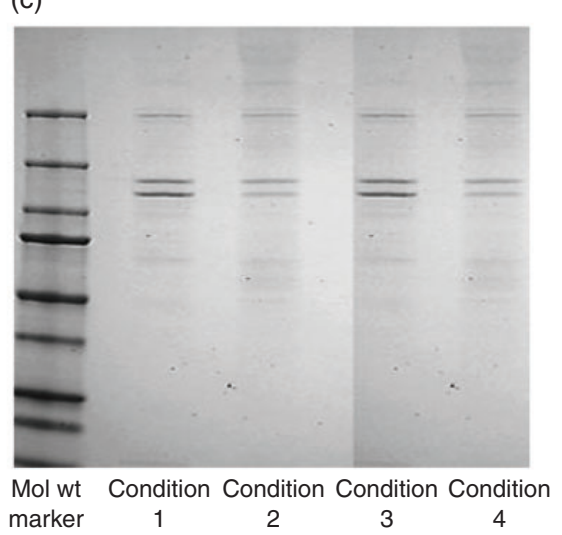

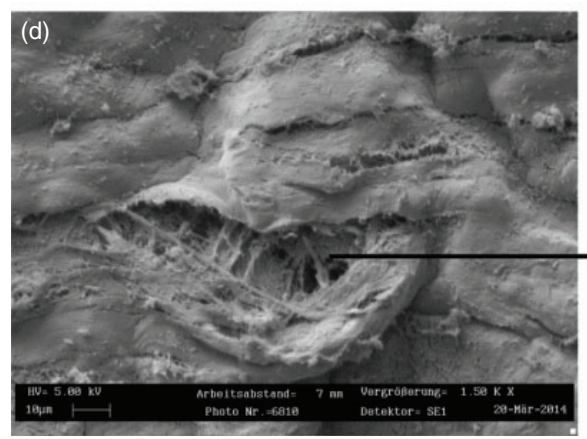

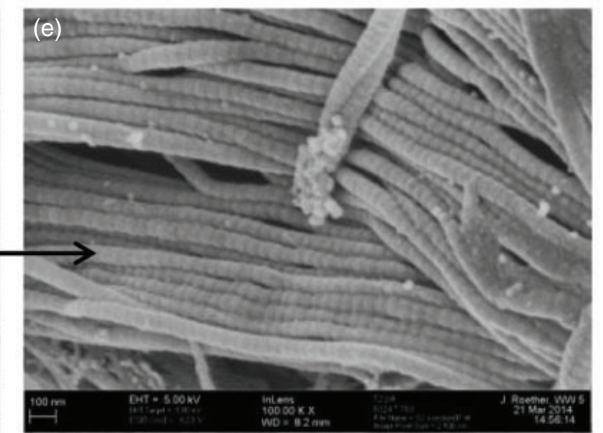

Figure 3. (a) Collagen quantification and analysis: results are reported as ug of collagen per mg of wet tissue weight, and percentage of collagen compared amongst samples treated under the different conditions and control. $* P<0.01-0.05 ; * * P<0.001-0.01$ and $* * * P<0.00 \mathrm{I}$. Digital image of SDS-PAGE showing the patterns of collagen type I bands (stained with coomassie blue) in (b) commercial collagen type I, II and control (native cartilage); and (c) in the cartilage scaffolds obtained after conditions I, 2, 3 and 4. The protein marker is a commercial ladder with $10-250 \mathrm{kDa}$. (d) Scanning electron microscopy (SEM) micrographs of cartilage scaffold obtained follow condition 3 and (e) inset showing collagen fibre morphology at higher magnification.

of the radical initiator system. Following the introduction of the Dc tissue, the overall profile showed an additional peak at between $\delta 6.9$ and $7.3 \mathrm{ppm}$ indicative of the Dc tissue (Figure 4(e)).

\section{In vitro stability study: Gel permeation chromatography}

Hydrogels with and without the biological tissue were immersed in simulated body fluid (SBF) for a period of
1,14 , and 30 days. GPC was used to confirm the functionalization of the alginate and PVA macromers and to characterize the soluble and released gel components that were collected throughout the process. From the molecular weight distribution curve, the hydrogels showed no discernible change in the low-molecular weight alginate (12-40 KDa) (peak 1) over the 30-day period (Figure 5(a)). However, the high-molecular weight PVA (30-70 KDa) (peak 2) over the same period showed a small increase in the molecular 
Table I. Proteomics analysis.

\begin{tabular}{|c|c|c|c|}
\hline PAN & Common proteoglycans & Length $(\mathrm{AA})$ & $\mathrm{Mw}(\mathrm{Da})$ \\
\hline P45846 & Dermatopontin; dermatan sulfate & 183 & 21,997 \\
\hline PI0859 & Hyaluronan and proteoglycan link protein I; & 354 & 40,289 \\
\hline P79385 & Lactadherin; A & 409 & 45,767 \\
\hline Q290II & Aggrecan core protein; & 537 & 58,641 \\
\hline Q27972 & Chondroadherin cartilage leucine-rich protein; & 361 & 40,915 \\
\hline P98160 & Basement membrane-specific heparan sulfate proteoglycan core protein; Perlecan; & 4391 & 469,307 \\
\hline P50609 & Fibromodulin & 376 & 43,245 \\
\hline Q80WM5 & Hyaluronan and proteoglycan link protein 3 ; & 359 & 40,768 \\
\hline PI3608 & Aggrecan core protein; cartilage-specific proteoglycan core protein; & 2364 & 246,625 \\
\hline Q28343 & Aggrecan core protein; cartilage-specific proteoglycan core protein; & 2333 & 240,843 \\
\hline P55290 & Cadherin-13; heart cadherin; truncated cadherin; & 713 & 78,263 \\
\hline Q96S86 & Hyaluronan and proteoglycan link protein 3 ; & 360 & 40,922 \\
\hline Q05443 & Lumican; corneal keratan sulfate proteoglycan 37B core protein & 342 & 38,785 \\
\hline Q9TTB4 & Fibromodulin; keratan sulfate proteoglycan lumican; & 147 & 16,693 \\
\hline Q9XSD9 & Decorin; AltName: full=bone proteoglycan II; & 360 & 39,928 \\
\hline O35367 & Keratocan; keratan sulfate proteoglycan keratocan; & 351 & 40,433 \\
\hline Q9TTB4 & Fibromodulin; keratan sulfate proteoglycan lumican; & 147 & 16,693 \\
\hline P02452 & Collagen alpha- $I(I)$ & 1464 & 139,109 \\
\hline Q15II3 & Procollagen C & 449 & 48,014 \\
\hline Q02388 & Collagen alpha-I(VII) & 2944 & 295,563 \\
\hline Q96P44 & Collagen alpha-I (XXI) & 957 & 99,468 \\
\hline P04258 & Collagen alpha-I(III) & 1049 & 93,774 \\
\hline Q63870 & Collagen alpha-I(VII) & 2944 & 295,576 \\
\hline Q05722 & Collagen alpha-I (IX) & 921 & 92,196 \\
\hline Q8CG08 & Collagen triple helix & 245 & 26,479 \\
\hline P02454 & Collagen alpha-I (I) & 1453 & $138,12 \mid$ \\
\hline P05997 & Collagen alpha-2(V) & 1499 & 145,073 \\
\hline P02466 & Collagen alpha-2(I) & 1372 & 129,720 \\
\hline Q91717 & Collagen alpha-I(II) & 1486 & 142,428 \\
\hline P20785 & Collagen alpha-I(VI) & 1019 & 108,097 \\
\hline Q7SIB2 & Collagen alpha-I(IV) & 229 & 25,393 \\
\hline P85I54 & Collagen alpha-2(I) & 1040 & 93,308 \\
\hline P20849 & Collagen alpha-I (IX) & 921 & 91,974 \\
\hline P02465 & Collagen alpha-2(I) & 1364 & 129,220 \\
\hline PI4282 & Collagen alpha-I(VIII) & 744 & $73,45 I$ \\
\hline 046392 & Collagen alpha-2(I) & 1366 & 129,556 \\
\hline P20908 & Collagen alpha-I(V) & 1838 & $|83,77|$ \\
\hline PI5988 & Collagen alpha-2(VI) & 1022 & 109,289 \\
\hline Q9XSJ7 & Collagen alpha-I (I) & 1460 & 138,930 \\
\hline Q04857 & Collagen alpha-I(VI) & 1025 & 108,602 \\
\hline P0246I & Collagen alpha-I(III) & 1466 & $|38,73|$ \\
\hline P2848I & Collagen alpha-I (II) & | 487 & |42, I 38 \\
\hline Q9YIB4 & Collagen alpha-I(I) & 1450 & $|37,73|$ \\
\hline PI2III & Collagen alpha-3(VI) & 3177 & 344,015 \\
\hline A6NMZ7 & Collagen alpha-6(VI) & 2263 & 247,415 \\
\hline PI2109 & Collagen alpha-I(VI) chain; & 1028 & 108,642 \\
\hline $\mathrm{PI} 2110$ & Collagen alpha-2(VI) chain; & 1019 & 108,692 \\
\hline P20909 & Collagen alpha-I $(X I)$ chain; & 1804 & 181,245 \\
\hline P0C2W8 & Collagen alpha-I(I) chain; & 1057 & 94,735 \\
\hline PI2I07 & Collagen alpha-I (XI) chain; & 1806 & 181,278 \\
\hline P08I 23 & Collagen alpha-2(I) chain; & 1366 & 129,470 \\
\hline Q997I5 & Collagen alpha-I (XII) chain; & 3063 & 333,481 \\
\hline Q28083 & Collagen alpha-I (XI) chain; & 911 & 89,369 \\
\hline
\end{tabular}


Table I. Continued

\begin{tabular}{|c|c|c|c|}
\hline PAN & Common proteoglycans & Length (AA) & $\mathrm{Mw}(\mathrm{Da})$ \\
\hline PI3944 & Collagen alpha-I(XII) & 3124 & 340,930 \\
\hline Q60847 & Collagen alpha-I(XII) & 3120 & 340,562 \\
\hline Q8C6K9 & Collagen alpha-6(VI) & 2265 & 246,565 \\
\hline Q02788 & Collagen alpha-2(VI) & 1034 & 110,446 \\
\hline P08253 & 72 kDa type IV collagenase; & 660 & 73,863 \\
\hline Q6P4Z2 & Collagen alpha-I(II) & 1492 & $|42,86|$ \\
\hline Q05707 & Collagen alpha-I (XIV) & 1796 & $|93,70|$ \\
\hline Q80X19 & Collagen alpha-I (XIV) & 1797 & 193,198 \\
\hline P02453 & Collagen alpha-I (I) & 1463 & 139,106 \\
\hline PI3942 & Collagen alpha-2(XI) & 1736 & $17 \mid, 992$ \\
\hline QIRMU3 & Procollagen-proline,2-oxoglutarate-4-dioxygenase & 534 & 61,062 \\
\hline Q32S24 & Collagen alpha-2(XI) & 1736 & 172,439 \\
\hline P02459 & Collagen alpha-I(II) & |487 & $|4|, 993$ \\
\hline
\end{tabular}

weight (Figure 5(b)) and a decrease in PDi (indicative of a measure of the distribution of molecular mass in a given polymer sample). Hydrogels incorporating Dc tissue showed a small decrease both in the low and higher molecular weight (peak 1) but had a stable PDi over the 30-day period (Figure 5(c)). This suggested that minimum amounts of un-polymerised PVA and alginate products and salts were eluted into the SBF solution over a period of 30 days for the hydrogels. However, in the presence of the Dc tissue, the amount of uncross-linked components of the mixture was greater. Hence, an increase in the alginate and PVA un-polymerized products after 30 days was observed.

\section{Mechanical analysis}

The hydrogel with and without Dc tissue was subjected to mechanical analysis. The Young's Modulus (ratio of stress over strain) for the hydrogel without Dc tissue was $0.25 \pm 0.07$ and $0.46 \pm 0.31 \mathrm{KPa}$ when De tissue was included. The Poisson Ratio was $0.50 \pm 0.07$ without tissue and $0.39 \pm 0.07 \mathrm{KPa}$ with tissue (Table 2).

\section{Bioactivity of the hybrid hydrogel}

The distribution of the biological tissue within the hydrogel was assessed using H\&E-stained histological images. Hydrogels with no Dc tissue showed few open pores and a fairly homogenous appearance, with fragments of pink eosinic staining of either the alginate or the PVA (Figure 6(b)). Hydrogel containing De tissue showed a random distribution of the tissue ranging in size 50-100 $\mu \mathrm{m}$ within the hydrogel (Figure 6(c)). During the processing of these hydrogels, the alcohol dehydration stage had resulted in vacuolation around the tissue which was artefactual. Following seeding with BM-MSC, both types of hydrogels were effective in promoting the development of a multilayered feature containing cells with varying morphology illustrating that the hydrogels were capable of supporting cells and therefore not cytotoxic (Figure 6(d), (e) (h) and (i)). As early as day 3 in both hydrogel groups, cells could be seen undergoing proliferation (i.e. cells were positive for ki-67) (Figure 6(f), (g) (j) and (k)).

\section{Discussion}

Poly(lactic acid) (PLA) and poly(ethylene glycol) PLGA polymers have previously been used for tissue engineering applications. However, neither polymer has the desired optimum cell environment, unlike biological ECM. Numerous synthetic and natural polymer-based hydrogels exist, but here we show an original bioactive hydrogel, in which the polymers are covalently joined to a biological component (decellularised porcine auricular cartilage) via methacrylate derivation and addition.

This hybrid bioactive hydrogel was therefore developed to exploit the molecular characteristics of biological tissue and the mechanical properties of natural and synthetic polymers for tissue engineering application. The outcome was a hydrogel with the potential to actively communicate with the surrounding environment (cells and ECM) and the mechanical strength to ensure structural longevity. This hydrogel has potentially wide ranging clinical applications such as intervertebral disc repair, cartilage-based prosthesis (e.g. nose and ears). Additionally, when combined with cells and 3D bio-printing, it could be utilised as a controlled cell therapy delivery system.

\section{Production of an acellular scaffold}

Four different methods were used to decellularise porcine auricular cartilage, which could be incorporated as 


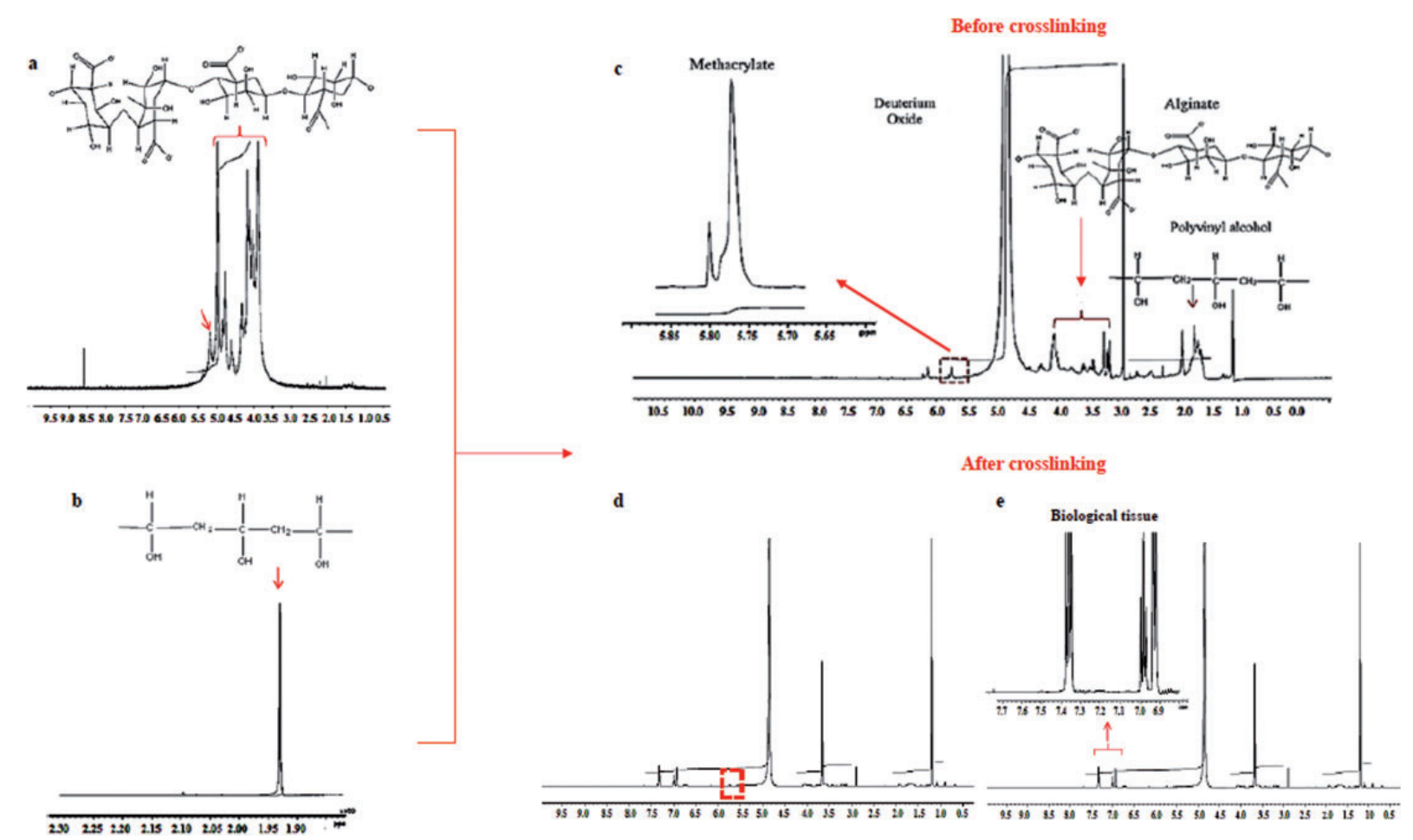

Figure 4. Structural composition of the hybrid hydrogel. IH NMR spectrum of alginate (a), polyvinyl alcohol (b) and the uncrosslinked MA-alginate in D2O (c). The characteristic vinylic peaks (between $\delta 5.7$ and 5.8 ppm) of the uncross-linked polymer are pointed out by a red arrow (c). The characteristic vinylic peaks (between $\delta 5.7$ and $5.8 \mathrm{ppm}$ ) were not displayed after cross-linking (d). The peaks representing the biological tissue were seen between ( $\delta 6.8$ and $7.4 \mathrm{ppm})$ highlighted in red and expanded in the inset (e).

the biological component in a bioactive hydrogel. Those methods for decellularization, using different reagents, with different enzymatic steps were designed to create the best scaffold that preserves the structural integrity of the ECM while allowing the biological cues to drive cell attachment and proliferation. Combinations of hypertonic and hypotonic solutions are known to lyse the cells by simple osmotic effects thereby dissociating DNA from the proteins. ${ }^{15}$

In condition 1, hypertonic and hypotonic solutions with no enzymes were used to induce osmotic shock with subsequent cell lysis. However, this method was ineffective in removing the nuclei acid from the tissue. Similarly, enzymatic conditions 2 and 3 utilising endonucleases, DNAse/RNase at varying concentrations to cleave the nucleic acids also proved to be ineffective. However, there was no major detrimental impact observed on the remaining macro-architecture of the ECM. ${ }^{16,17}$ The use of benzonase nuclease (condition 4) was ineffectual at removing cells and contradicted Dijkman et al. who suggested that benzonase ${ }^{\mathbb{B}}$ nuclease would be more effective than exonucleases since they cleave nucleotides mid-sequence. Dijkman et al. ${ }^{18}$ observed that the combination of Triton X-100, sodium deoxycholate and the enzymes was responsible for the clearance of $99 \%$ of DNA in less dense heart valve tissue. However, in this study although a higher enzyme concentration was used, the dense microarchitecture of the cartilage tissue may have hindered penetration. Although enzymes (e.g. nucleases) can provide high specificity for removal of cell residues, complete cell removal by enzymatic treatment alone was shown to be insufficient.

When cartilage tissue is immersed in hypertonic and hypotonic solutions, four mechanisms of transfer take place between the different phases in the cartilage. Those 'mechanisms' are hydration, ion exchange, acidification and alkalization. ${ }^{19,20}$ Surface complexation changes caused due to ion exchange and acid-base reactions on the sites of the permanent charge or X-sites on the cartilage are known to induce either swelling or shrinking. ${ }^{15,19,21}$ Distilled water is low in ionic strength and alkalinity; therefore, the tissues exhibit an isotropic free swelling followed by contraction or shrinkage when immersed in a hypotonic solution. This solution contains tris hydrochloride $(\mathrm{HCl})$ and in its presence both ion exchange and surface complexation reactions co-operate to induce contraction or shrinkage of the samples. In the hypertonic solution, considerable swelling is observed due to the presence of sodium ions 


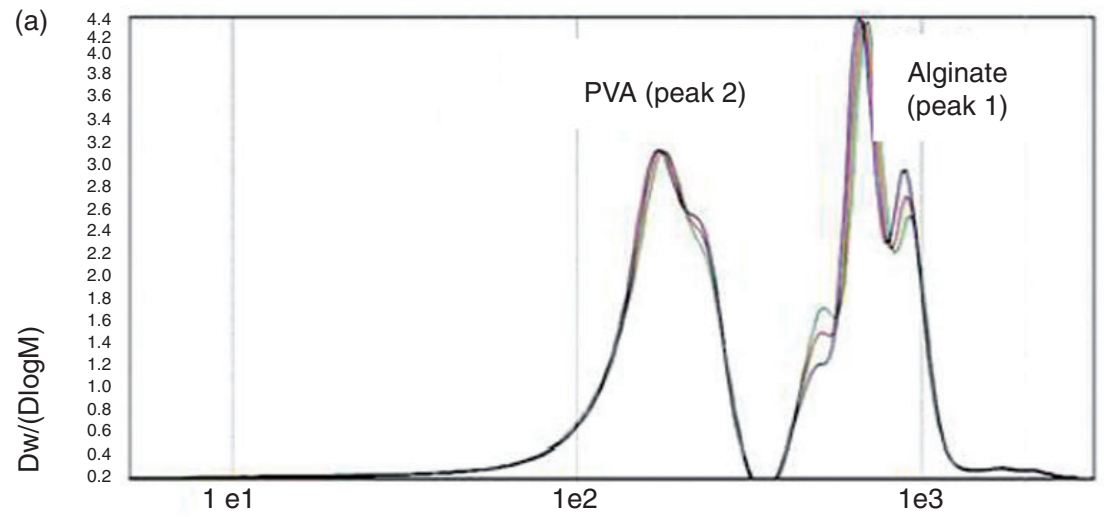

Day 1

Day $14=$

Day $30=$

(b)

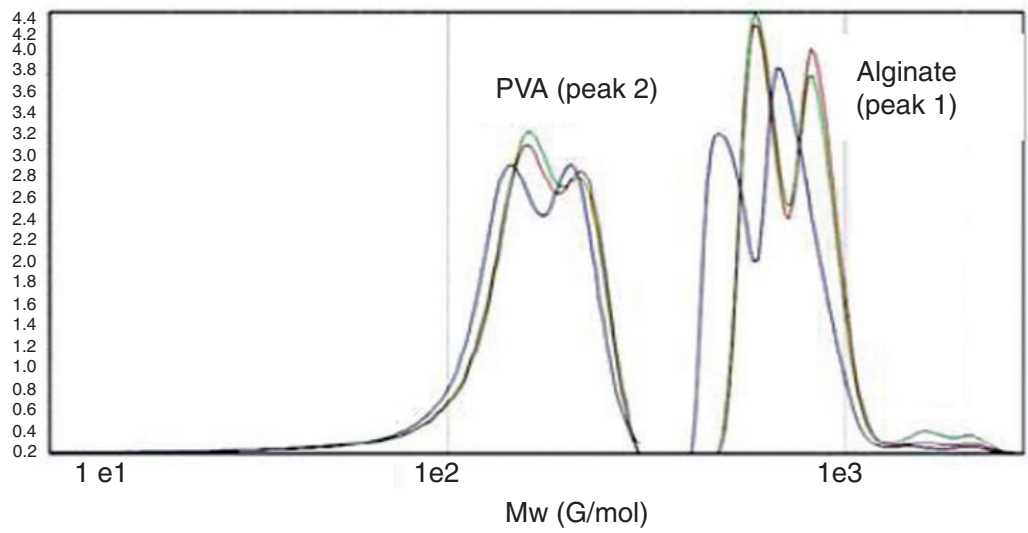

(c)

\begin{tabular}{|c|c|c|c|c|c|c|}
\hline \multirow{2}{*}{$\frac{\text { Sample name }}{\text { Hydrogel }}$} & \multicolumn{3}{|c|}{ Alginate (Peak 1) } & \multicolumn{3}{|c|}{ PVA (Peak 2) } \\
\hline & $\mathrm{Mn}\left(\mathrm{g} / \mathrm{mol}^{-1}\right)$ & $\mathrm{Mw}\left(\mathrm{g} / \mathrm{mol}^{-1}\right)$ & PDi & $\mathrm{Mn}\left(\mathrm{g} / \mathrm{mol}^{-1}\right)$ & $\mathrm{Mw}\left(\mathrm{g} / \mathrm{mol}^{-1}\right)$ & PDi \\
\hline Day 1 & 700 & 760 & 1.08 & 120 & 170 & 1.41 \\
\hline Day 14 & 700 & 760 & 1.06 & 131 & 180 & 1.34 \\
\hline Day 30 & 700 & 760 & 1.08 & 150 & 180 & 1.17 \\
\hline Hydrogel with Dc & $\operatorname{Mn}\left(\mathrm{g} / \mathrm{mol}^{-1}\right)$ & $\operatorname{Mw}\left(\mathrm{g} / \mathrm{mol}^{-1}\right)$ & PDi & $\mathrm{Mn}\left(\mathrm{g} / \mathrm{mol}^{-1}\right)$ & $\operatorname{Mw}\left(\mathrm{g} / \mathrm{mol}^{-1}\right)$ & PDi \\
\hline Day 1 & 730 & 780 & 1.08 & 150 & 170 & 1.16 \\
\hline Day 14 & 720 & 770 & 1.06 & 150 & 170 & 1.14 \\
\hline Day 30 & 630 & 680 & 1.08 & 140 & 160 & 1.16 \\
\hline
\end{tabular}

Number average molecular weight Mn; Weight average molecular weight Mw; Poly dispersity index (PDi) : is the ratio of the weight average molecular weight to the number average molecular weight.

Figure 5. Hybrid bioactive hydrogel degradation analysis. Molecular weight data for hydrogel with and without biological tissues using gel permeation chromatography. ${ }^{*} \mathrm{MN}$ : Number average molecular weight, *Mw: Weight average molecular weight, *PDi: Polydispersity index.

$\left(\mathrm{Na}^{+}\right)$and EDTA. EDTA as a divalent chelator and enzyme inhibitor is known to inhibit swelling by binding to divalent ions such as $\mathrm{Ca}^{+}, \mathrm{Mg}^{+}$; however, at a low $\mathrm{pH}(<4.0)$ and low concentrations $(0.05 \mathrm{M})$, EDTA is completely protonated becoming ineffective as a chelator thereby causing severe swelling. ${ }^{20,22}$ In the incubation buffer, however, the tissue exhibits shrinkage. With the rapid uptake of the $\mathrm{Ca}^{+2}$ ions in the incubation buffer by the s-GAG, a structural transition takes place that causes a reduction in the water content 
of the tissues. The $\mathrm{Ca}^{+2}$ ions form a direct coordinative bond with the sulphate groups of the s-GAGs causing the highly ordered structure of the s-GAG to be disrupted, this in turn leads to an extensive displacement of water causing the tissue to shrink. ${ }^{23}$

A denaturing extraction buffer was used to extract the s-GAGs and collagen from the Dc tissue as it is effective in solubilising the strongly bound ECM components and destabilising the ionic and disulphidedependent proteins. ${ }^{24}$ The s-GAGs have immobilised

Table 2. Comparison of representative values of Young's Modulus (YM; ratio of stress over strain) and Poisson ratio was taken for comparison among samples: hydrogel with and without biological tissue (BL).

\begin{tabular}{lll}
\hline Sample name & YM (MPa) & Poisson ratio \\
\hline Hydrogel & $0.248 \pm 0.07$ & $0.503 \pm 0.07$ \\
Hydrogel with BT & $0.46 \pm 0.31$ & $0.386 \pm 0.07$ \\
\hline
\end{tabular}

sulphate and carboxyl groups which become charged in solution and contribute a negative fixed charge density (FCD). ${ }^{21}$ However, when the $\mathrm{pH}$ of the surrounding fluid is changed due to acid-base reactions, the charge of both collagen and s-GAG changes ${ }^{21}$ resulting in the creation of a net osmotic pressure $(\pi)$ within the tissue which causes the tissue to swell increasing its ability to bear the load. ${ }^{21}$ The hydrated tissue also becomes more easily accessible to the proteases released from the lysosomes which in turn lead to the degradation of the s-GAGs. ${ }^{20}$ This in turn causes a steeper swelling pressure on the tissue adding greater stress on the collagen network and causing them to degrade. ${ }^{21}$

The high enzyme concentrations used in condition 2 also had an effect on the collagen structure of the tissue, causing the collagen component to defibrillate. This could also cause proteoglycans to be lost from the tissue resulting in lower s-GAG content when compared to those treated with lower enzyme
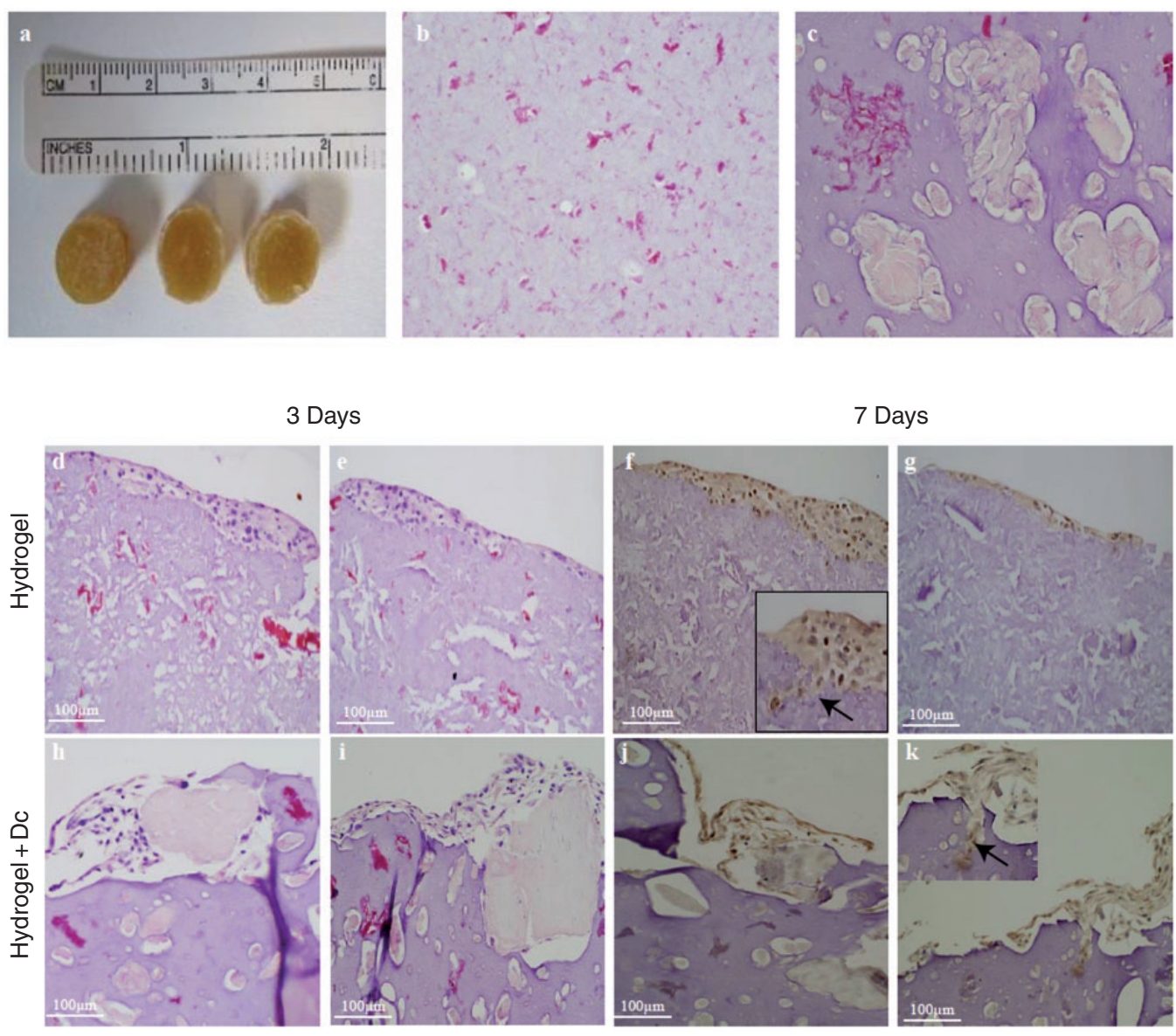

Figure 6. Bioactivity of the hybrid hydrogel. Pictures showing (a) the macro appearance of the hydrogels; (b) histological images (H\&E) of hydrogel without biological tissue and (c) with biological tissue. Photomicrographs showing the in vitro biocompatibility tests using bone marrow-derived mesenchymal stem cells (BM-MSC) seeded on the hydrogels without (d, e, f g) and with (h, i, j, k) biological tissue for three and seven days. Both hydrogel types can support a multi-cellular layered structure, composed of proliferating cells (seen after ki-67 immuno-staining at $f, g$ and $j, k$ ) as early as three days. 
concentrations (condition 3). Dc tissue treated under condition 3 retained the major s-GAG such as aggrecan and hyaluronan compared to the control when analysed using proteomics. Other small proteoglycans such as decorin, fibromodulin and lumican known to interact with the collagen fibril, influencing the fibrillar architecture by mechanical buffering and hydration were also found to be unaffected. Similarly, matrillin interacts with collagen and s-GAG forming a complex extracellular network. ${ }^{25}$ Most importantly, glycoprotein micro fibrils such as fibrillins covering the elastin fibers essential for maintaining the integrity of the elastin fibre were present. ${ }^{3}$ These results further indicate that the hypertonic and hypotonic solutions used in condition 3 had minimal effect on the ECM in contrast to other decellularising solutions such as Triton X-100 and SDS used in other studies. ${ }^{15}$

\section{Hybrid hydrogel synthesis and characterization}

Alginate and PVA are biocompatible and biodegradable polymers currently used to create hydrogels for tissue engineering. ${ }^{26}$ In order to prepare hybrid hydrogels with robust mechanical properties and long-term stability, pendant methacryloyl groups were introduced into the alginate and PVA main chains via 2-AEMA. PVA can form hydrogen bonds among PVA chains and with other polymer chains by virtue of the hydroxyl groups present in its repeating units and due to the high hydrophilic forces. ${ }^{26,27}$ In previous studies, PVA and xanthan have been freeze-thawed and crosslinked. ${ }^{28}$ In alginates, the polysaccharides are linked together by hydrophilic groups that form covalent bonds with other polymers and subsequent noncovalent bonds with biological tissues. However, the methacrylated alginate hydrogels have active end groups, which form covalent cross-links with other polymers in the presence of initiators. ${ }^{29}$ The methacrylated hydrogels are superior in properties compared to the ionically cross-linked polymers, which are known to display weak structural integrity due to the dissolution of divalent cations into the surrounding environment. ${ }^{1}$ These polymers with modified functional groups (methacrylates) then undergo free radical polymerization in the presence of an initiator ${ }^{30}$ and have been used for the polymerization of poly(propylene fumarate)/PPF. Previous studies have revealed the successful encapsulation of chondrocytes in methacrylated alginates cross-linked with APS/TEMED. ${ }^{29}$ The hydrogels were subjected to further physical cross-linking by repeated air-drying and freeze-thawing cycles as this method induces physical cross-linking by entangling the polymer chains and causing them to cross-link. Covalently and physically cross-linked hydrogels therefore are known as double cross-linked hydrogels which have an advantage of self-healing when the strain on the hydrogel is removed. ${ }^{12}$

Spectroscopic analysis of the samples showed disappearance of the methacryoyl groups on the alginate and PVA backbone, indicating successful cross-linking. ${ }^{2}$ The hydrogels with Dc tissue also revealed full disappearance of the methacryoyl groups but the peaks indicating the Dc tissue was still present thereby confirming that the tissue was non-covalently linked. This feature is important as it contributes to the degradation of the hydrogels. Degradability of hydrogels is an important criterion in tissue engineering since the degradation rate of the biomaterial has to be tailored to the rate and extent of new tissue formation. ${ }^{1}$ Previous studies have shown that methacryloyl groups introduced into the alginate chains for covalent crosslinking affect the elastic modulus of the hydrogels thereby making them mechanically robust. ${ }^{2,31}$ This in turn can control the swelling behaviour and the degradation rate of the hydrogels. The ionically cross-linked alginates conversely display a weaker structural integrity due to the faster dissolution of ions from the gels making it difficult to control the degradation rate; as a result, several studies have preferred intermolecular covalent cross-linking of alginate with a wide range of controllable mechanical properties. ${ }^{1}$ PVA in turn is known for its high hydrophilicity and increased water absorption. ${ }^{13}$ In our study, we observed that the hydrogels without Dc tissue exhibited only minimal degradation.

The presence of the Dc tissue in the hybrid hydrogels, however, contributed to a slightly increased degradation rate at the end of 30 days. Since the extent and method of crosslinking are also known to have an influence on the physical properties, ${ }^{32}$ the non-covalent links, as well as the restricted number of crosslinks, may have contributed to an increased water imbibition thus subsequently affecting degradation rate.

The compressive mechanical properties and Poisson's ratio of hydrogels ${ }^{2,33}$ with and without biological tissue were assessed. Both set of hydrogels had a tissue-like compliance due to the crosslinks formed between the sterically entangled polymer chains known to increase elasticity and hardness. ${ }^{2}$ However, the hydrogels without Dc tissue possessed a higher degree of flexibility which was also evident in the higher Poisson's ratio (i.e. a cylindrical hydrogel with increased flexibility expands radially when compressed axially). The porosity of the hydrogels could have also contributed to its flexibility. However, the polymer chains entangled with the Dc tissue occupying the pores may have had an increased number of interfibrillar crosslinks which prevented the polymer chains from sliding past each other, thus increasing the stiffness of the material and reducing its flexibility. ${ }^{32}$ As a result, the energy required to fracture these hydrogels were 
greater when compared to just the hydrogels. The hydrogels with Dc tissue retained mass stability and appreciable geometrical changes after compression; however, further in vitro and in situ studies are required.

Following crosslinking, the hydrogels appeared opaque when compared to the transparent nanoporous gels which are monophasic and have a homogenous distribution of crosslinks throughout the hydrogel. A change in the environmental $\mathrm{pH}$ possibly due to the initiators TEMED/APS and a heterogeneous distribution of the crosslinking junctions are likely to have contributed to the formation of an opaque hydrogel. ${ }^{2,33}$ Histological analysis revealed macro and micropores along with a random distribution of the Dc tissue within. Matrix degradation products and remaining chemicals following decellularisation are known to impact on the biocompatibility of engineered samples following implantation. ${ }^{34}$ Both types of hydrogels supported cells attachment and proliferation with potential for differentiation. Interestingly, cells seeded on the hydrogel containing Dc tissue, migrated to the fragments of biological scaffolds, perhaps in response to retained molecular cues in those scaffolds. This follows the premise that the collagen fiber architecture and ECM products of biological samples not only play a critical role in determining their mechanical behavior, ${ }^{34}$ but can also provide the ideal environment for directing cell interaction (attachment, migration and proliferation) as well as presenting growth factors to cells, which ultimately can lead to differentiation. ${ }^{34,35}$

This bioactive hydrogel has a number of potential clinical applications which all require further investigation. One potential application is for hard tissues such as the replacement of the nucleus pulposus in intervertebral disc degeneration (IVD). IVD occurs when the core proteins, aggrecan and GAGs are reduced in the nucleus pulposus (NP), causing a loss in the ability of the disc to retain water. The dehydrated disc loses hydrostatic pressure and is then unable to distribute the mechanical load evenly resulting in significant pathology. A number of biological and artificial samples are available as replacements to restore the anatomy, mobility and stability of the degenerate disc. ${ }^{1,36}$ By tuning the mechanical properties of our hydrogel by the degree and type of crosslinking, the natural load transfer phenomenon seen in intact IVD could be mimicked and the normal biomechanics of the degenerated IVD could be restored. In addition, as a scaffold, it can also be used to promote tissue repair by stimulating proteoglycans and collagen production in vivo by the resident cells. These hybrid bioactive hydrogels can also be used for 3D cell growth and growth factor delivery relevant to angiogenesis and differentiation especially since the nanofibers mimic the ECM dimensions.

Finally, it may also be possible to use a modified version of the bioactive hydrogel to create prosthesis where the original damaged or diseased tissue has a high cartilage content, e.g. nose and ears. Since the starting material for this bioactive hydrogel was cartilage retrieved from porcine ear, i.e. hyaline cartilage, it already possesses the correct molecular cartilage fingerprint making it ideal for the development of such tissue engineered and bespoke prosthesis.

\section{Conclusion}

To our knowledge, this bioactive hydrogel is unique in its composition. It has been developed to exploit the molecular cues on biological tissues for enhanced cellular interaction and exploit bio mechanical properties of both natural and synthetic polymers. The hybrid bioactive hydrogel is cyto-compatible and has the potential for multiple clinical applications.

\section{Declaration of Conflicting Interests}

The author(s) declared no potential conflicts of interest with respect to the research, authorship, and/or publication of this article.

\section{Funding}

The author(s) disclosed receipt of the following financial support for the research, authorship, and/or publication of this article: This study was funded by The Paul Foundation to whom the authors are greatly indebted.

\section{ORCID iD}

Karin V Greco (D) http://orcid.org/0000-0002-8484-415X

\section{References}

1. Jeon O, Bouhadir KH, Mansour JM, et al. Photocrosslinked alginate hydrogels with tuneable biodegradation rates and mechanical properties. Biomaterials 2009; 30: 2724-2734.

2. Bencherif SA, et al. Injectable preformed scaffolds with shape-memory properties. Proc Natl Acad Sci USA 2012; 27: 19590-19595.

3. Frantz C, Stewart KM and Valerie MW. The extracellular matrix at a glance. $J$ Cell Sci 2010; 123: 4195-4200.

4. Greco KV, Francis L, Somasundaram M, et al. Characterisation of porcine dermis scaffolds decellularized using a novel non-enzymatic method for biomedical applications. J Biomater Appl 2015; 30: 239-253.

5. Schindler M, Nur EKA, Ahmed I, et al. Living in three dimensions: 3D nanostructured environments for cell culture and regenerative medicine. Cell Biochem Biophys 2006; 45: 215-227. 
6. Uriel S, Labay E, Megan MS, et al. Extraction and assembly of tissue-derived gels for cell culture and tissue engineering. Tissue Eng Part C Methods 2009; 15: 309-321.

7. Johnson KR, Leight JL and Weaver VM. Demystifying the effects of a three-dimensional microenvironment in tissue morphogenesis. Meth Cell Biol 2007; 83: 547-583.

8. Levental KR, Yu H, Kass L, et al. Matrix crosslinking forces tumor progression by enhancing integrin signalling. Cell 2009; 139: 891-906.

9. Pelham RJ and Wang Y. Cell locomotion and focal adhesions are regulated by substrate flexibility. Proc Natl Acad Sci USA 1997; 94: 13661-13665.

10. Lutolf MP and Hubbell JA. Synthetic biomaterials as instructive extracellular microenvironments for morphogenesis in tissue engineering. Nat Biotechnol 2009; 23: 47-55.

11. Ehrbar M, Rizzi SC, Schoenmakers RG, et al. Biomolecular hydrogels formed and degraded via sitespecific enzymatic reactions. Biomacromolecules 2007; 8: 3000-3007.

12. Peak CW, Wilker JJ and Schmidt G. A review on tough and sticky hydrogels. Colloid Polym Sci 2013; 291: 2031-2049.

13. Giménez VNM, Ronda JC and Cadiz V. Poly (vinyl alcohol) modified with carboxylic acid anhydrides: crosslinking through carboxylic groups. J Appl Polym Sci 1997; 65: 1643-1651.

14. Kokubo T, Kushitani H, Sakka S, et al. Solutions able to reproduce in vivo surface-structure changes in bioactive glass-ceramic A-W. J Biomed Mater Res 1990; 24: 721-734.

15. Crapo PM, Gilbert TW and Badylak SF. An overview of tissue and whole organ decellularization processes. Biomaterials 2011; 32: 3233-3243.

16. Fitzpatrick JC, Peter MC and Franco MC. Effect of decellularization protocol on the mechanical behaviour of porcine descending aorta. Int J Biomat. 2010; 2010: 1-11.

17. Funamoto S, Nam K, Kimura T, et al. The use of highhydrostatic pressure treatment to decellularize blood vessels. Biomaterials 2010; 31: 3590-3595.

18. Dijkman PE, Driessen MA, Frese L, et al. Decellularized homologous tissue-engineered heart valves as off-theshelf alternatives to xeno-and homografts. Biomaterials 2012; 33: 4545-4554.

19. Campo DR. Effects of cations on cartilage structure: swelling of growth plate and degradation of proteoglycans induced by chelators of divalent cations. Calcif Tissue Int 1988; 43: 108-121.

20. Gajo A and Loret B. The mechanics of active clays circulated by salts, acids and bases. J Mech Phys Solids 2007; 55: 1762-1801.

21. Loret B and Simões MFF. Articular cartilage with intra-and extrafibrillar waters-mass transfer and generalized diffusion. Eur $J$ Mech A/Solids 2007; 26: 759-788.
22. Maroudas A. Balance between swelling pressure and collagen tension in normal and degenerate cartilage. Nature 1976; 260: 808-809.

23. Werner A and Grunder W. Calcium-induced structural changes of cartilage proteoglycans studied by $1 \mathrm{H}$ NMR relaxometry and diffusion measurements. Magn Reson Med 1999; 41: 43-50.

24. Didangelos A, Yin X, Mandal K, et al. Proteomics characterization of extracellular space components in the human aorta. Mol Cell Proteomics 2010; 9: 2048-2062.

25. Klatt AR, Becker AK, Neacsu CD, et al. The matrilins: modulators of extracellular matrix assembly. Int $J$ Biochem Cell Biol 2011; 43: 320-330.

26. Kamoun EA, El-Refaie S, Kenawy Tamer M, et al. Poly (vinyl alcohol)-alginate physically crosslinked hydrogel membranes for wound dressing applications: characterization and bio-evaluation. Arab J Chem 2015; 8: 38-47.

27. Nkhwa S, Fernando KL, Kemal E, et al. Poly (vinyl alcohol): physical approaches to designing biomaterials for biomedical applications. Conf Papers in Sci 2014; 2014: 1-8.

28. Giannouli P and Morris ER. Effect of cryogenic treatment on the rheological properties of gelatin hydrogels. J Bio Comp Poly 2003; 22: 621-636.

29. Sun JY, Zhao XH, Illeperuma WRK, et al. Highly stretchable and tough hydrogels. Nature 2012; 489: 133-136.

30. Chou AI, Akintoye SO and Nicoll SB. Photo-crosslinked alginate hydrogels support enhanced matrix accumulation by nucleus pulposus cells in vivo. Osteoarth Cart 2009; 17: 1377-1384.

31. Smeds KA, Pfister-Serres A, Miki D, et al. Photocrosslinkable polysaccharides for in situ hydrogel formation. J Biomed Mater Res 2001; 54: 115-121.

32. Charulatha $\mathrm{V}$ and Rajaram A. Influence of different crosslinking treatments on the physical properties of collagen membranes. Biomaterials 2003; 24: 759-767.

33. Joshi A, Fussell G, Thomas J, et al. Functional compressive mechanics of a PVA/PVP nucleus pulposus replacement. Biomaterials 2006; 27: 176-184.

34. Badylak SF, Fretes DO and Gilbert TW. Extracellular matrix as a biological scaffold material: structure and function. Acta Biomater 2009; 5: 1-13.

35. Nam Ki H, Smith AST, Lone $\mathrm{S}$, et al. Biomimetic three-dimensional tissue models for advanced highthroughput drug screening. $J$ Lab Autom 2015; 20: 201-215.

36. Francis L, Meng D, Knowles JC, et al. Multi-functional P (3HB) microsphere/45S5Bioglass ${ }^{(3)}$-based composite scaffolds for bone tissue engineering. Acta Biomater 2010; 31: 2806-2815.

37. Urban JPG and Roberts S. Degeneration of the intervertebral disc. Arthritis Res Ther 2003; 5: 120-130. 